\title{
TRADUCGIÓN Y NORMALIZACIÓN LINGÜÍSTICA O EL TRIUNFO DE LA DIVERGENCIA A LA FUERZA: EL CASO DE LE PETIT PRINCE ANDALUZ
}

\author{
TRANSLATION AND LINGUISTIC STANDARDIZATION \\ OR THE ACCOMPLISHMENT OF DIVERGENCE \\ BY FORCE: THE CASE OF LE PETIT PRINCE \\ IN ANDALUSIAN SPANISH
}

\author{
Santiago Del Rey Quesada \\ Universidad de Sevilla \\ sdelrey@us.es \\ orcid: 0000-0001-9871-4498 \\ Elena Méndez García de Paredes \\ Universidad de Sevilla \\ emendez@us.es \\ orcid: 0000-0002-7262-5232
}

RESUMEN: En este trabajo analizamos las inconsistencias y contradicciones en que se sustenta la traducción ¿andaluza? de Le petit prince. Discutimos la idea de normalización lingüística subyacente a su propuesta y demostramos cómo, desde una perspectiva teórica, el traductor ignora consciente o inconscientemente el espacio variacional en que se inscriben la lengua española y sus variedades (no sólo geográficas), y de qué modo, en la práctica, el autor produce una hipertrofia en su texto de los fenómenos de interferencia lingüística consustanciales a todo proceso de traducción, buscando de forma premeditada y constante la divergencia respecto de la traducción española.

Palabras clave: variación lingüística; traducción; estándar lingüístico;

interferencia lingüística; andaluz.

Abstract: This paper aims to shed light on the inconsistencies and contradictions to be found in an Andalusian? translation of Le petit prince. We discuss the idea of linguistic normalization that underlies this study. From a theoretical perspective, we demonstrate that the translator consciously or unconsciously ignores the variations (which are not only geographical) that conform the Spanish language. Furthermore, we argue that this translation produces a hypertrophied text, characterized by a constant and deliberate effort to break away from the standard Spanish version.

Keywords: linguistic variation; translation; linguistic standard; linguistic interference; Andalusian Spanish.

Recepción: 19 de diciembre de 2019; aceptación: 18 de julio de 2020.

D.R. (c) 2022. Nueva Revista de Filología Hispánica Licencia Creative Commons Attribution-NonCommercial (CC BY-NC) 4.0 International 
LA RECEPCIÓN DE EL PRINCIPITO ANDALUZ

EN DIFERENTES ÁMBITOS DE LA VIDA PÚBLICA*

A finales del año 2017 aparecía una publicación de la que se hicieron eco numerosos medios de comunicación —no sólo regionales- ${ }^{1}$ y que despertó un gran revuelo en las redes sociales: la traducción al andaluz ${ }^{2}$ del clásico de Antoine de Saint-Exupéry Le petit prince, firmada por el autodenominado Huan Porrah. Recientemente, un grupo de informáticos, programadores y diseñadores gráficos, reunidos bajo el nombre de Andalugeeks, volvió a despertar la polémica en torno a la traducción de Porrah al crear el primer transcriptor del español al andaluz ${ }^{3}$, tomando como base la ortografía propuesta en dicha traducción, que, a su vez, se funda en la que consensúa en diversas "Huntah d'ehkritoreh" la Zoziedá pal Ehtudio'el Andalú (ZEA), a la que el propio Porrah pertenece.

La fuerza motriz que impulsa esta publicación es un intento de demostrar que la variedad andaluza constituye un tipo de lengua apto para llevar a cabo un proceso de traducción, en cuanto que dispone de un sistema gráfico adecuado para representar su pronunciación y una estructura lexicosemánti-

* Este artículo se inscribe en el marco de dos proyectos de investigación: "Construcción Histórica y Proyección Social de la Imagen del Habla Andaluza” (US-1257660), concedido por la Consejería de Economía, Conocimiento, Empresas y Universidad de la Junta de Andalucía dentro del Programa de I+D+I del Operativo FEDER Andalucía 2014-2020, liderado por Elena Méndez García de Paredes, y "Tradicionalidad discursiva e idiomática, sintaxis del discurso, traducción y cambio lingüístico en la historia del español moderno: prosa (pre-)periodística/ensayística y literaria (TradHisMod 2)" (PGC2018-097823-B-I00), concedido por el Ministerio de Ciencia, Innovación y Universidades, cuya investigadora principal es Araceli López Serena.

${ }^{1}$ Cf. notas de prensa en El Mundo (https:/ / www.elmundo.es/f5/descubre/2017/05/ 09/5911970eca4741b42d8b4656.html), El Español (https:/ / www.elespanol.com/cultura/libros/20170509/214728966_0.html) o $A B C$ (https:/ / sevilla.abc.es/andalucia/sevi-principito-andaluz-perdon-ninoh-dabel-le-dedikao-ehte-libro-201705121701_noticia.html), entre otros. Sobre la recepción mediática de la traducción, véase MARín 2019, pp. 89-92.

${ }_{2}$ No había habido, hasta donde nuestro conocimiento alcanza, ninguna tentativa previa de traducción íntegra al andaluz de algún texto clásico en el sentido literario. Las decisiones ortográficas de Juan Ramón Jiménez o Blas Infante no constituyeron nunca un sistema rígido y, por lo demás, no repercutieron sobre el ámbito de la traducción.

${ }^{3}$ Cf. nota de prensa en el Diario de Sevilla (https://www.diariodesevilla.es/andalucia/traductor-espanol-andaluz-EPA-principito-andaluh_0_1327667354.html). 
ca y gramatical capaz de transmitir los contenidos de la historia narrada, sin tener que recurrir al corsé impuesto por la variedad estándar del español. Pero, sobre todo, Er prinzipito ha de entenderse como una reacción perlocutiva para la "dignificación del andaluz" de carácter (de)mostrativo, es decir, una traducción patriótica o identitaria (Villena 2016) promovida por ciertos sectores andalucistas, en respuesta a comentarios despreciativos y desvalorizadores sobre el andaluz, difundidos mediáticamente (cf. Méndez García de Paredes 2019).

Con todo, no hay que interpretar la publicación de Er prinzipito ni como el resultado de una ansiada demanda social reclamada política y lingüísticamente por los andaluces, ni tampoco como el documento de un conjunto de expertos lingüistas y normadores designados para ello por La Junta de Andalucía. Y de ningún modo es el modelo de lengua ideal por el que la mayor parte de andaluces orienta sus realizaciones verbales en las situaciones de comunicación cotidianas. Como se señala en el habanteo, es una propuesta individual de Huan Porrah, y así deberíamos tomarla, pero sin olvidar que se publica no para traducir la obra de Saint-Exupéry al idiolecto andaluz de su traductor — hecho, a todas luces, carente de sentido-, ni siquiera al dialecto de su comarca malagueña de "La Algarbía", sino - como es obvio - para ser elevada a la categoría de "lengua o habla social". Esto es, como la primera intervención traductológica "en andaluz" que trata de fijar la heterogeneidad y polimorfismo de unas hablas en su ortografía, morfosintaxis, semántica, léxico y pronunciación como un andaluz de andaluces y para los andaluces.

El fuerte componente ideológico que subyace a la identidad lingüística de los hablantes, sobre todo en una época en que la conciencia (meta)lingüística se ha convertido en tema de discusión cotidiana en diferentes redes sociales, se manifestó de diversa forma en las opiniones que poblaron redes sociales como Twitter, Facebook o WhatsApp en el año de la publicación. La mayoría de las opiniones resultó negativa, como vemos en (i), donde la enunciadora tacha de "ofensiva" la versión de Porrah, y acusa la dificultad que le supone entender el texto. Otros comentarios aludían al problema de la representatividad de la identidad andaluza. Algunos usuarios (ii) se quejan de que la traducción no representa lingüísticamente a todos los andaluces. El debate fue intenso no sólo en las redes sociales, sino que a pie de calle, en los días inmediatamente anteriores 
y posteriores a la presentación del libro, el cruce de opiniones entre andaluces fue generalizado y recurrente. Incluso figuras públicas de reconocido prestigio se pronunciaron, lo que contribuyó a extender la repercusión mediática de la traducción. Así, Arturo Pérez Reverte (iii) desacreditaba en tono irónico la validez de la traducción de Porrah, desacreditación reforzada en un segundo tuit (iv) mediante el uso de un argumentum ad personam.

(i) Como lectora y como andaluza, que se publique un libro como "Er Prinzipito" me ofende. He intentado leer el comienzo y no he entendido nada (valoración de Er prinzipito en Twitter, 9.V.2017).

(ii) Faltáis el respeto a parte de Andalucía. En granaino debería ser "Er Prinzipito y qe pollah", y vendría con tapa. \#Si. YunaPolla \#GranáExiste (SAT Sevilla, "Presentación de «Er prinzipito» en nuestra sede del Pumarejo"; valoración de Er prinzipito en Twitter, 9.V.2017).

(iii) Recomiendo mucho asistir. Conviene saber lo que nos espera. O lo que estamos teniendo ya (Pérez Reverte sobre la presentación de Er prinzipito en Twitter, 9.V.2017).

(iv) Y como dije antes, éste es el antropólogo traductor der Prinzipito youtube.com/watch?v=tcl4dN... (Pérez Reverte sobre Huan Porrah en Twitter, 9.V.2017).

No faltaron voces, sin embargo, que justificaban la traducción de Huan Porrah como objeto de estudio. El tuit que se reproduce en (v) es confirmación de ello. La defensa de Er prinzipito como objeto de estudio venía abanderada por filólogos de formación que reconocían en la traducción un esfuerzo considerable, cuando no encomiable, de normalización. Se propiciaba así el debate en el que se invitaba a participar, mediante etiquetas (tags), a reconocidos divulgadores de la ciencia lingüística en las redes sociales ${ }^{4}$. También algunos youtubers egresados de Filología (vi) utilizaban su título como argumento de autoridad para defender la iniciativa de Porrah, aun sin demostrar

${ }^{4}$ Este Jüan Agüirre etiquetó, por ejemplo, a semevadelalengua (http:// www.semevadelalengua.es), trasunto de la profesora Carlota de Benito Moreno (Universidad de Zúrich), que cabalmente rehusó hacer comentario alguno. 
conocimiento alguno sobre el fenómeno de la variación y sobre la naturaleza de las variedades lingüísticas, ni sobre los parámetros de la situación de comunicación que determinan los procesos de selección estilística efectuados por el autor del texto original que requieren ser trasladados por el traductor al texto meta (Villena 2016).

(v) Me voy a tener que mojar con el tema de \#ErPrinzipito: se tiene que valorar cientifíco-filológicamente como posible objeto de estudio (tuit de Jüan Agüirre en el que reivindica el estudio de Er prinzipito, 11.V.2017).

(vi) No se puede normalizar... Hay muchos dialectos, mejor no intentar nada (el youtuberVanfunfun en defensa de la traducción andaluza).

La traducción de Porrah también ha sido defendida por representantes del mundo académico — no olvidemos que el propio Porrah pertenece a este ámbito ${ }^{5}$. Tal es el caso de Martín González (2017), quien, desde una perspectiva biologicista, condena, apelando al espíritu de Blas Infante — el "padre" de la "patria" andaluza, bandera del nacionalismo político andaluz-, la falta de consideración en que se ha tenido el andaluz como "sistema lingüístico humano"; con su artículo, el estudioso adopta una supuesta actitud "científica" que, sin embargo, contribuye a perpetuar tópicos como el del orgullo de los andaluces, la discriminación lingüística, etcétera:

no hay nada malo en que los andaluces nos sintamos orgullosos de cómo nos expresamos. Es muy positivo y muy necesario darles visibilidad a los sistemas lingüísticos autóctonos y hacer que se conozcan en su complejidad y en su variedad, como muy bien animaba a hacer Blas Infante. Pero, sigamos también a Infante en el andalucismo que proponía como ideal de humanidad y consideremos la defensa del andaluz dentro de una defensa global de cualquier sistema lingüístico humano. En este sentido, una comprensión profunda del fenómeno de las lenguas desde el punto de vista defendido aquí, en consonancia con el conocimiento científico actual, ayudaría a fundamentar las bases en contra de la discriminación lingüística del andaluz al mismo tiempo que nos haría tomar conciencia como andaluces de que tampoco podemos reproducir la Sevilla.

${ }^{5}$ Es profesor de Antropología en la Universidad Pablo de Olavide de 
estigmatización de ningún tipo de variedad, ni local ni exterior. También evitaría que tuviéramos que depender exclusivamente del grado de sensibilidad social promovido desde la política como parte de una estrategia ideológica democratizadora o inclusiva de singularidades autóctonas. Y, por supuesto, haría que propuestas como las que han sido presentadas recientemente nunca fuesen recibidas con la sarta de insultos y de opiniones producto de visiones discriminatorias, sino que fuesen debatidas desde el respeto académico y social que merecen, entre otros motivos por el esfuerzo encaminado que suponen en la lucha contra la nefasta discriminación lingüística que los andaluces seguimos padeciendo (Martín González 2017; cursivas añadidas).

El propio estudioso reclama de los especialistas una actitud científica que justifique el rechazo "desproporcionado, discriminatorio, visceral" que en ocasiones ha recibido la traducción de Porrah $^{6}$. Con este trabajo, nuestro propósito consiste en adoptar, como demanda este autor, una actitud crítica sobre el texto que analizaremos. Con todo, queremos dejar claro desde el principio de este artículo que la traducción de El principito es producto de una ficcionalización del andaluz propuesta por Huan Porrah, y como tal no puede erigirse en objeto de estudio equiparable a ninguna muestra real de la(s) variedad(es) andaluza(s). En cualquier caso, sí creemos que el lingüista debe dar una respuesta a la relativa "preocupación" o "sorpresa" social que generó su publicación. Un trabajo como éste debe servir para explicar que la propuesta de Huan Porrah no es perjudicial como ejercicio de pasatiempo literario y que, incluso, puede ser divertida si se circunscribe a la esfera de lo lúdico - e incluso de lo irónico. Pero desde el momento en que pretende

6 "Llama la atención la virulencia de los ataques propagados por la prensa y las redes sociales. Abundan los insultos, incomprensiblemente se han cebado contra los proponentes atacando sus supuestas adscripciones político-sindicales y, desde un periódico de larga historia en nuestro país, hasta se han mofado en términos clasistas de la ropa con la que aparecen en las fotos publicadas, una muestra perfecta del nivel intelectual y ético de quienes así han actuado. Es más, también sorprende la reacción extrema de quienes, por sus especialidades académicas y profesionales, se supone deben opinar desde el conocimiento y el sosiego, pero que, sin embargo, han caído en lo mismo, llegándolas a tachar de disparate y de ridiculización del andaluz. En mi opinión, se ha vuelto a poner de relieve la necesidad de preguntarse por qué se muestra ese comportamiento tan desproporcionado, discriminatorio, visceral y $\tan$ falto de cualquier justificación científica" (MARTíN GoNZÁlez 2017; cursivas añadidas). 
rebasar el ámbito de lo anecdótico y recibir apoyo institucional - como lo reciben las "Huntah d'ehkritoreh" que organiza la $\mathrm{ZEA}^{7}$ - , es el deber de los expertos precaver a las instituciones de la peligrosidad de intentos de normalización banales e ignorantes de la realidad histórica de las lenguas (cf. Méndez García de Paredes y Amorós 2018). El mismo reconocimiento institucional procura una iniciativa que surgió casi paralelamente a la publicación de Er prinzipito andaluz: la de la promoción de una "Academia Andaluza de la Lengua", que se presentaba como "una Academia para el estudio y dignificación de las formas andaluzas", con voluntad de erigirse en "una fundación pública cuyo presupuesto se incluiría en los Presupuestos Generales de la Comunidad Autónoma Andaluza”, y que se justificaba recurriendo al manido tópico, no demostrado por nadie hasta el momento (cf. Cano Aguilar 2008, pp. 89-111; Narbona 2009, pp. 47-48), del complejo de inferioridad lingüística de los hablantes andaluces, ya que, según los promotores —ambos, de nuevo, filólogos egresados-, "a nivel de dignificación de nuestras hablas..., es del todo imposible luchar contra el complejo lingüístico andaluz sin una política de participación activa social que incida sobre el nivel de conciencia de las personas".

En las siguientes páginas nos ocuparemos de los problemas que plantea la traducción de Porrah como modelo de norma escrita andaluza, reflexionando sobre cómo el proceso de traducción crea un resultado insólito y falseador de la(s) $\operatorname{variedad}(\mathrm{es})$ lingüística(s) andaluza(s) y haciendo ostensible el desconocimiento, consciente o inconsciente, del autor de esta propuesta acerca del espacio variacional de las lenguas, desconocimiento que invalida su texto como modelo de normalización e invita a desechar cualquier intento de instrumentalización del andaluz como realidad separada del español en el ámbito político-social ${ }^{8}$ en que pretende desenvolverse el promotor de esta y otras propuestas de "dignificación" del andaluz.

${ }^{7}$ Lo que forma parte capital de su programa: "perkurà er rekonozimiento zoziá y ihtituzioná y entangariyà lah herramientah prezizah pa zu zehlío literario" (cf. http://www.zea-andalu.com/kién-zemoh/).

${ }^{8}$ Estamos plenamente de acuerdo con Marín (2019, p. 83) cuando afirma que "la traducción de Juan Porras no tiene una función comunicativa, sino exclusivamente política: reivindicar una variedad dialectal andaluza que, en opinión del traductor, se encuentra oprimida por la colonización castellana de Andalucía”. 
TRADUCGIÓN, NORMALIZACIÓN Y ESTANDARIZACIÓN LINGÜÍSTICA

Para los defensores de una identidad andaluza excluyente, el paso más apremiante que deben seguir las instituciones autonómicas es el de la normalización de la(s) variedad(es) lingüística(s) andaluza(s). El intento de normalización del andaluz supondría, sin embargo, una reducción arbitraria de la multiplicidad de formas que se dan en las hablas andaluzas, y la imposición de una única forma de hablar andaluz sería frustrante para la mayoría de los andaluces ${ }^{9}$ (cf. Narbona 1999). En los siguientes términos lo expresa Narbona:

Si toda propuesta de normalización lingüística persigue — deliberadamente o no- algo imposible, como es corregir — por vía legal y administrativa - el proceso evolutivo natural de las lenguas mediante una planificación de carácter político, la pretensión de normalizar el andaluz —una modalidad (o, mejor, un conjunto de modalidades) únicamente hablada del español, que... ofrece abundantes y notables diferencias internas - tendría que comenzar por resolver ciertas cuestiones: ¿Tiene alguien legitimidad y autoridad para imponer, o proponer, ciertos usos (insistimos, hablados) a aquellos que no los practican? ¿Con qué propósito se promoverían iniciativas que "obligarían" a algunos andaluces (o a todos) a alterar algo (o bastante) de su comportamiento idiomático, sin que vean las ventajas que de ello podrían obtener? La primera ni siquiera se ha planteado. No ha habido, ni puede haberlo, ningún intento serio en tal sentido (Narbona 2009, p. 48).

En efecto, el vernáculo andaluz presenta diferentes soluciones en la región como resultado de las circunstancias en que se desenvolvieron las variedades del castellano y de otros romances medievales durante la reconquista y repoblación de la región (ss. XIII-XVI), las cuales pudieron favorecer la activación de una cierta inestabilidad latente en la pronunciación de la lengua medieval con soluciones diferentes de las que surgieron en las variedades norteñas del castellano peninsular. La documentación analizada de fines del siglo XIV ofrece algunas

9 Cf. también Marín (2019, p. 85), quien apunta en esta misma dirección al tratar el problema de la ortografía de Er prinzipito: "lo cierto es que todo proceso de codificación lingüística (especialmente en el terreno ortográfico) supone inevitablemente una imposición sobre la libertad de los hablantes". 
muestras de çeçeo (no siempre fiables), que sugieren una simplificación temprana en el orden de las sibilantes para el reino de Sevilla y su área de influencia, más generalizada y testimonialmente también más segura desde finales del siglo xv en adelante (Menéndez Pidal 1962; Alonso 1969; Lapesa 1985; Frago 1993; Ariza 1997; Cano 2013; Narbona et al. 2014). En la actualidad lo vernacular se manifiesta como un continuum de hablas locales de realización polimórfica que convergen y divergen entre sí, de manera que proporcionan una imagen heterogénea de variabilidad geográfica, social, situacional y estilística. No obstante, se constata también cierta recurrencia con respecto a determinados rasgos que se dejan categorizar como patrones de uso compartidos por toda la comunidad andaluza: elisión de sonidos consonánticos a final de palabra; aspiración de /s/ implosiva en interior de palabra o de grupo fónico, con (+/-) fenómenos asimilatorios de geminación y/o simplificación de grupos consonánticos; neutralización de /1/ implosiva, realizada como vibrante; pérdida de /d/ intervocálica, particularmente en los participios $-a d a>a ́$, $-a d o>a o$; $-i d o / a>i o / i a$.

En cambio, hay otros fenómenos que, desde el origen de estas hablas, dividen verticalmente Andalucía en dos zonas no siempre coincidentes (occidental y oriental). Las soluciones faríngeas /h/ en contextos etimológicos propios de las prepalatales medievales se apartan de los vernáculos que siempre tuvieron en tales contextos velar fricativa $/ \mathrm{x} / ;$ los que desde su constitución practican la distinción con variantes andaluzas de $/ \mathrm{s} / \mathrm{y} / \theta />[\mathrm{s}]$ y $[\theta]$ lo hacen con respecto a los que sesean con /s/ coronal o predorsodental y a los que cecean con variantes andaluzas $[\theta]\left[\theta^{\mathrm{s}}\right]$; las áreas que mantienen las vocales finales proyectadas como consecuencia de la lenición de consonantes implosivas finales contrastan con las áreas que no tienden a la abertura vocálica. Así las cosas, los modelos implícitos de ejemplaridad idiomática en hablantes cultivados oscilan en relación con patrones de divergencia de las hablas septentrionales o de convergencia con éstas (Villena 2008 y 2008a) y tienden a evitar variantes socialmente estigmatizadas por su adscripción a hablantes no instruidos, precisamente las que se proponen para Er prinzipito.

La propuesta ortográfica de la ZEA, en la que se basa la de la traducción de Porrah, promotor, a su vez, de dicha propuesta, supone una selección arbitraria de signos con un pretendido valor identitario particularizado que no puede contentar a ninguna comunidad lingüística dentro de Andalucía. En Er 
prinzipito no hay una ortografía de carácter simbólico que remita unívocamente a la imagen verbal de la palabra y haga abstracción de su polimórfica pronunciación andaluza de carácter contextual; se llevan a cabo más bien intervenciones marcadas ortográficamente para "transcribir" (que no escribir), sin mucha profusión de signos fonéticos un texto divergente del estándar ortográfico del español, para hipercaracterizarlo como andaluz. En esto es en lo que parece consistir la denominada "orzión ortográfika ehnolinguíhtika" (cf. habanteo) que cada escritor podría ajustar a su propio idiolecto; de ahí que el deseo de normalización que subyace a una propuesta tal sea, además, inane, pues, como ya se ha dicho,

no parece, en absoluto, que un trabajo de ese tipo [el de normalización] sea ni necesario ni exigido por la sociedad andaluza, que es en lo lingüístico tan dual como en su adscripción nacional...: se siente tan andaluza como española, y no piensa renunciar a ninguno de esos dos elementos integrantes de su identidad social (Méndez García de Paredes 2009, p. 305).

Históricamente ha habido intentos conscientes de reflejar una cierta habla andaluza en textos literarios de impronta popular, filtrada estilísticamente en la ortografía y en el léxico con rasgos de carácter (+/-) estereotípicos y recurrentes, dados con una función de evocación y de realismo costumbrista para reflejar ambientes y caracterizar personajes (Mondéjar 1990). La muestra más temprana es un auto de navidad, La infancia de Jesu Christo, del malagueño Gaspar Fernández de Ávila, del siglo XVIII (Ariza 1994). Pero hasta en las propuestas de escritura de Machado y Álvarez — seguidas también por Rodríguez Marínpara transmitir en las letras de los cantes flamencos el hondo sentir de la vida de un pueblo, lo habitual siempre fue una acomodación desigual y poco sistemática de rasgos marcados como andaluces que intervienen y modifican la imagen de la palabra escrita para reproducir la pronunciación dialectal. Los ejemplos literarios pueden multiplicarse; basta una muestra, sintetizada luego en una tabla con los procedimientos más arraigados en la lengua literaria:

Pieresita'h e la caye se güerban grano'h de sá y me caigan en lo o'ho'h si yo te güerbo a mirá. 
Las lusesita'h que briyan

De noche en er sementerio,

Están disiendo a lo'h vivo'h

Que se acuerden de lo'h muerto'h

(Machado y Álvarez "Demófilo", Coplas flamencas) ${ }^{10}$.

- Mi pare tié un reló e plata.

-Y er mío, un cabayo.

-Y er mío una ejcopeta

(J.R. Jiménez, Platero y yo, 1914).

Mare, me jeché arena zobre la quemaúra.

Te yamé, te yamé dejde er camino...

¡Nunca ejtuvo ejto tan zolo!

Las yama me comían,

mare, yo te yamaba, y tú nunca benía

(J.R. Jiménez, "La carbonerilla quemada", en Historias, 1908-1912).
¡Malas puñalás me den!...
Pues así hubiera vivío, con jambre entretenío, que eso entretiene tamién:
Pero me di en cavilá que los chiquiyos yoraban...
que los males arresiaban
con rumbos de temporá...;
y dije: Manué Romero:
apriétate los calsones;
deja las cavilasiones
que no dan pringue ar puchero.
Pa el probe que no es leío,
el son del entendimiento
no es más que un calentamiento
que remata en un jipío.
¿Qué estás jecho un carcamá
y pa que un mengue te coma?
¡Más pasó San Pedro en Roma
y arrepara dónde está!

(J.C. de Luna, "El último alijo", en El Cristo de los gitanos, 1942).

10 "Apuntes para un artículo literario [fonética andaluza]", Revista Mensual de Filosofia, Literatura y Ciencias, 2 (1870), pp. 37-42, apud MondéJAR 2001, p. 60. 
TABLA 1

\section{Rasgos lingüísticos tipificados como andaluces en la literatura costumbrista}

\begin{tabular}{|c|c|c|c|}
\hline $\begin{array}{l}\text { Yeísmo, "y": } \\
\text { "cabayo", "caye" } \\
\text { [caballo, calle]. }\end{array}$ & $\begin{array}{l}-d r->r: \text { "pare-mare" } \\
\text { [padre, madre]. }\end{array}$ & $\begin{array}{l}\text { ch > sh: "mushasho- } \\
\text { zarzishón" } \\
\text { [muchacho, } \\
\text { salchicón]. }\end{array}$ & $\begin{array}{l}\text { Metátesis: "naide- } \\
\text { probe" [nadie, } \\
\text { pobre]. }\end{array}$ \\
\hline $\begin{array}{l}\text { Сeceo, "z": "ze } \\
\text { ba" [se va]. }\end{array}$ & $-d>\varnothing$ : "sé-zé" [sed] & $\begin{array}{l}\text {-n > Ø: "bihe der } \\
\text { Carme" }\end{array}$ & $\begin{array}{l}\text { Aféresis: "ehmayao- } \\
\text { andaliah, onde } \\
\text { ande" [desmayado, } \\
\text { sandalias, donde]. }\end{array}$ \\
\hline $\begin{array}{l}\text { Seseo, "s": } \\
\text { "haser- serillo" } \\
\text { [hacer-cerillo]. }\end{array}$ & $\begin{array}{l}-z>\varnothing: \text { :bo- die" } \\
\text { [voz, diez]. }\end{array}$ & $\begin{array}{l}\text {-s > h: "ehto- ehpá" } \\
\text { [esto, espada]. }\end{array}$ & $\begin{array}{l}\text { Ustedes }+2^{\mathrm{a}} \\
\text { pers.: "qué queréi } \\
\text { uhtedeh". }\end{array}$ \\
\hline $\begin{array}{l}\text { Aspiración, "j", } \\
\text { "h": “diho- } \\
\text { oho", "jumo", } \\
\text { "ejcopeta", } \\
\text { "jechar". }\end{array}$ & $\begin{array}{l}\text {-1 >-r: "güerbe- } \\
\text { mardito" [vuelve, } \\
\text { maldito]. }\end{array}$ & $\begin{array}{l}\text { Segmentos } \\
\text { protéticos: } \\
\text { "ehtiherah-arrahcá- } \\
\text { entabía" [tijeras, } \\
\text { rascar, todavía]. }\end{array}$ & $\begin{array}{l}\text { Orden de palabras: } \\
\text { "más nada-máhná", } \\
\text { "más nunca", "más } \\
\text { nadie". } \\
\text { Régimen } \\
\text { preposicional: "lo vi } \\
\text { de venir". }\end{array}$ \\
\hline $\begin{array}{l}-d->\varnothing: \text { "quean" } \\
\text { "na" [quedan, } \\
\text { nada]. }\end{array}$ & $\begin{array}{l}\text {-1> Ø: "papé- } \\
\text { munizipá" [papel, } \\
\text { municipal]. }\end{array}$ & $\begin{array}{l}\text { Segmentos } \\
\text { paragógicos: "asín" } \\
\text { [así]. }\end{array}$ & $\begin{array}{l}\text { Léxico: "saborío- } \\
\text { colorao-malahe- } \\
\text { buya, candela", } \\
\text { etcétera. }\end{array}$ \\
\hline
\end{tabular}

La normalización conduce a la estandarización. Uno de los cauces más importantes para la estandarización de una lengua es y ha sido históricamente la actividad traductora (cf. Del Rey 2016). El objetivo de Porrah es valerse de unos procedimientos de traducción para divulgar las normas ortográficas consensuadas por la ZEA, con lo cual hace pasar por traducción lo que no es más que la aplicación de un supuesto ideal ortográfico para el andaluz que asume y aglutina la mayor capacidad diferencial posible respecto del estándar castellano, considerado por el autor como una fuerza antagonista y represora de la variación interna del andaluz. De ahí que la propuesta de Porrah sea contraria al funcionamiento histórico de las lenguas, fundamentalmente porque su propuesta se basa en una variedad ficticia constituida por una gran mayoría de rasgos que los propios hablantes andaluces no reconocen, ya no digamos como prestigiosos, sino incluso como representativos de su variedad 
de habla en diferentes tipos de situaciones comunicativas ${ }^{11}$. Sin embargo, para hacer veraz esa variedad ficticia - anclada, según él, en la algarabía malagueña-, recurre al ejercicio de la traducción, ésta sí una actividad histórica que contribuye a la generación de lenguas estándares como una de las vías más fructíferas de la elaboración lingüística ${ }^{12}$.

Entre los supuestos universales traductológicos, Toury (1995, p. 267) menciona la ley de estandarización creciente, formulada por Baker (1996, p. 183) como el universal de normalización, que explica el hecho de que los textos traducidos supongan las manifestaciones más representativas del estándar de una lengua ${ }^{13}$. La formulación de este universal se orienta a explicar la tendencia generalmente compartida por las traducciones a favorecer las características más prototípicas de la lengua meta. Una traducción, pues, presenta, de manera general, los rasgos que los miembros de una comunidad lingüística dada perciben como menos marcados en su lengua o variedad. En este sentido, la propuesta de Porrah se contradice con esa tendencia general compartida por los productos de la actividad traductora en cualquier lengua.

Ideológicamente, desde la época del Romanticismo, el proceso de traducción a lenguas "minoritarias" se concibe asimismo como un proceso de dignificación lingüística:

Cuando en una relación jerárquica los hablantes de una lengua o variedad considerada inferior quieren elevar el estatus de esa lengua, hablamos de dignificación. Y aquí entra en el escenario la traducción: una de las vías más eficaces de dignificación es la traducción de textos con prestigio abierto; textos admirados culturalmente, tanto por sus lenguas de origen como por su prestigio particular (Kabatek 2018, p. 31).

11 En esta misma línea de argumentación se expresa MaRín (2019, p. 81).

${ }^{12}$ La elaboración lingüística, que es tanto extensiva como intensiva (cf. Koch y Oesterreicher 2007 [1990], pp. 187-188), explica cómo una naciente lengua de cultura, hasta un determinado momento usada sólo en situaciones prototípicas de la inmediatez comunicativa, consigue copar el ámbito de la distancia a partir del desarrollo de sus propias tradiciones discursivas y de los mecanismos lingüísticos apropiados para ello.

${ }^{13}$ Una crítica del concepto de universal traductológico, que se relaciona con el deseo expreso o implícito del investigador por equiparar las ciencias humanas con las naturales (véase López Serena 2019), puede leerse en Del Rey 2015. 
Claro que ese proceso de dignificación va ligado a la selección de una serie de variantes que son de uso aceptado y generalizado en determinada comunidad lingüística como formas susceptibles de participar en una variedad elaborada de lengua. Dichas formas no tienen por qué ser necesariamente prestigiosas, o sea, considerarse como típicos atributos de discursos habitualmente emitidos por hablantes cultos en situaciones formales. Basta con que se trate de formas aptas para su uso en cualquier situación comunicativa. Pero, por supuesto, el estándar de una lengua o de una variedad no puede descansar sobre formas que se restringen a contextos de enunciación informales.

En relación con estos diferentes tipos de formas lingüísticas a las que acabamos de referirnos, queremos aclarar que, desde el punto de vista de Del Rey (2021), el estándar representa una variedad que cabe situar en el centro de la cadena de variedades, un modelo formulado por Koch y Oesterreicher (2007 [1990], p. 42) que se replantea con una serie de modificaciones sustanciales en la Figura 1:

\section{FIGURA 1}

Nueva propuesta de la cadena de variedades según Del Rey (2021)

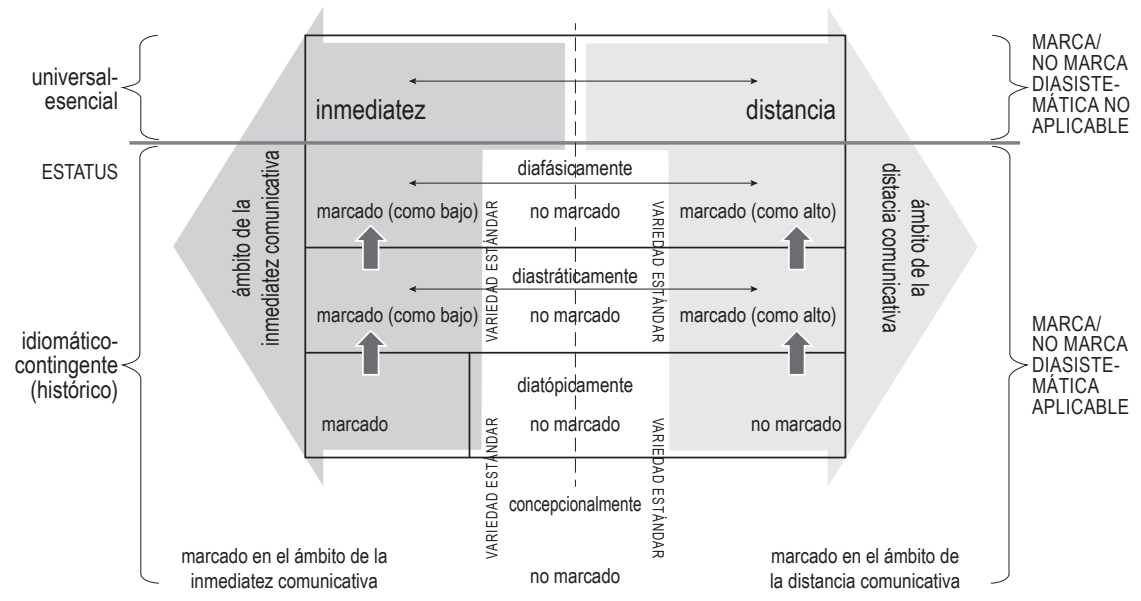

Según esta nueva propuesta, la variedad estándar se identifica con las variantes no marcadas de una lengua histórica determinada, si bien la concepción habitual del estándar se ha relacionado sobre todo con la parte derecha de la cadena de variedades. Lo que no ha ocurrido, y nunca podrá ocurrir, es que las for- 
mas que no sobrepasan el ámbito de la inmediatez comunicativa se postulen como variantes aptas para constituir la base de una variedad estándar, ya que las formas marcadas diastrática y diafásicamente como bajas, y por tanto concepcionalmente marcadas como propias del ámbito de la inmediatez comunicativa, comúnmente no se emplean, ni se validan, en todos los tipos de discurso, como sí ocurre con las formas no marcadas que, como tales, constituyen la variedad estándar y son susceptibles de usarse a lo largo y ancho de todo el espacio variacional de una lengua.

En este sentido, el proceso de traducción de Er prinzipito revela un claro desconocimiento de la variación diasistemática y concepcional de las lenguas. Pero, además, el análisis traductológico también revela un uso dirigido y artificial de otro tipo de variación que en Del Rey (2020) se ha denominado "basado en el contacto" (contact-based), y que se refiere a la selección de variantes en una determinada variedad como producto del contacto con otras variedades, hecho consustancial a los procesos de traducción. Al verter Le petit prince al andaluz, Porrah parte del contacto entre un estándar francés y un conjunto de variedades andaluzas que pretende reducir a una amalgama de rasgos diferenciadores para dotar el andaluz de personalidad lingüística en oposición al castellano estándar (peninsular). De esta forma, discutiremos en la siguiente sección cómo la variación basada en el contacto, en el caso de Er prinzipito, no sólo debe analizarse teniendo en cuenta las soluciones que el traductor elige en función de las formas que se encuentran en el texto fuente (TF), sino también —o sobre todo- en virtud de la traducción castellana más extendida (cf. infra, "Las traducciones de Le petit prince...”), de la que querrá divergir prácticamente en todo para potenciar el carácter genuino y diferenciador del andaluz respecto de la lengua "coercitiva" — precisamente ésa que es común a todos los andaluces, el español.

Para discutir los problemas que subyacen a la traducción de El principito desde la perspectiva traductológica y entender cómo concibe el autor esta propuesta de estandarización, nos basamos en una teoría de la interferencia lingüística inspirada en Kabatek (1997), que a su vez se fundamenta en ideas previamente desarrolladas por Weinreich (1967 [1953]) y Coseriu (1977) ${ }^{14}$.

${ }^{14}$ Nuestra idea de la interferencia también tiene puntos en común con el concepto de transfer, de TouRY (1995, p. 311), si bien no coincide plenamente con él.

Nueva Revista de Filología Hispánica (NRFH), LXX, 2022, núm. 1, 53-94 ISSN 0185-0121; e-ISSN 2448-6558; DOI: 10.24201/nrfh.v70i1.3784 
Aunque, por razones de espacio, no nos es posible detenernos en explicar con pormenor a qué se refiere cada una de las categorías que en Del Rey (2020) se distinguen a propósito de la variación basada en el contacto, bastará decir por el momento que la actitud de un traductor hacia el TF puede ser, en un determinado contexto de traducción, de convergencia o de divergencia. La convergencia y la divergencia pueden materializarse en fenómenos de interferencia positiva, es decir, fenómenos marcados de alguna manera en el texto meta (TM), o en fenómenos de interferencia negativa, fenómenos no marcados - en el caso del análisis traductológico, sólo perceptibles por el especial contexto de contacto que permite la comparación entre TF y TM. La interferencia positiva da lugar a tipos de interferencia con resultados directamente comprobables en los discursos producidos, en tanto que los elementos que ella crea resultan positivamente presentes en los textos; por el contrario, la interferencia negativa no produce elementos positivamente realizados en el discurso, es decir, no conducen a resultados anormales o agramaticales como consecuencia del contacto (cf. Del Rey 2020, pp. 213-216).

En el siguiente apartado comprobaremos cómo la actitud de Porrah ante los modelos de traducción que considera (explícita o implícitamente) es de exacerbada divergencia: abundan los fenómenos que denominamos de diferencia - cambio de una estructura del TF por otra de distinto tipo en el TM, aun cuando el mantenimiento del tipo no habría supuesto ningún problema en la lengua meta- y de hipercaracterización, desde el momento en que el traductor opta incesantemente por soluciones marcadas o más marcadas en el TM a propósito de las variantes que se encuentran en sus modelos —el TF declarado y la(s) traducci[ó]n(es) castellana(s) orientadoras de las soluciones diferenciadoras de su texto.

LAS TRADUCGIONES DE LE PETTT PRINCE Y LA DECLARACIÓN DE INTENCIONES DE ER PRINZIPITO

El clásico de Antoine de Saint-Exupéry, escrito en 1946, ha sido traducido a más de trescientas lenguas. La editorial alemana Tintenfa $\beta$ se ha empeñado en promover la traducción a lenguas minoritarias — dialectos italianos del norte, dialectos alemanes y patois franceses-, si bien se percibe en este esfuerzo una inten- 
ción lúdica que se postula como estrategia comercial, sin que se vislumbre ningún interés por promocionar estándares lingüísticos que puedan convertirse en modelo de lenguas descentralizadas. La traducción andaluza, sin embargo, trasciende este valor lúdico que utiliza la editorial para vender libros, pues se concibe como materialización de las reivindicaciones de la ZEA y, por tanto, aspira a convertirse en modelo de escritura de la variedad andaluza (sea esto lo que sea para los integrantes de dicha sociedad).

Para llevar a cabo el análisis del fallido intento del traductor en este sentido, nos basamos, además de en la versión de Porrah y en el original francés, en dos traducciones previas al español. La más conocida y reeditada es la del argentino Bonifacio del Carril, publicada siete años después del texto original. A pesar del origen americano del traductor, no hay que esperar encontrar en el texto ningún rasgo característico de la variedad geográfica que sería nativa al autor, algo que sí ocurre en la traducción de Sandra Caula de 2015, donde aparecen efectivamente formas prototípicas del español americano — si bien se prescinde de particularismos específicos de países y sólo se han seleccionado variantes panamericanas, muy particularmente el pronombre ustedes para el plural de la segunda persona. Asimismo, manejamos como textos de referencia dos traducciones, al extremeño y al murciano - ediciones también de corto alcance financiadas por editores ocasionales o editoriales minoritarias-, que permitirán observar hasta qué punto la versión de Porrah es conscientemente divergente respecto de los modelos que considera ${ }^{15}$.

La traducción "andaluza" de Le petit prince viene precedida por un pequeño proemio —que Porrah denomina "habanteo"16 — donde se declara cuál es la base para la escritura del andaluz, con lo cual hace ver que su propuesta de estandarización resulta particularista y contradictoria:

${ }^{15} \mathrm{Al}$ final del artículo se relacionan las ediciones y traducciones de Le petit prince que se tuvieron en cuenta para este estudio, con especificación de los datos de publicación.

${ }^{16}$ Palabra evidentemente relacionada con la forma etimológica ante, pero que no hemos conseguido documentar en ninguno de los repertorios de léxico andaluz al uso -ALEA 1993 [1961-1973], Alcalá Venceslada 1951, Alvar EzQuerra 2000, etcétera. 
Ze l'arbierte ar lehtó u lehtora d'ehte Er Prinzipito ke la zerxa dialehtá prinzipá ke ze maneha en ehta traduzión eh el andalú de l'Argarbía, komarka del ehe zentro-zú d'Andaluzía, alimentá kon argunoh beneroh d'otrah bariánteh dialehtaleh. ¿I por ké ehta bariedá dialehtá andaluza i no otra? La razón eh mu zenziya: pork'eh el andalú natibo ke maneha zu traduhtó, el abaho firmante H. Porrah, tan guena komo kuahkieriya otra, en er momento en ke no ezihte otabía ningún andalú ahuntao ([And $\left.{ }^{17}\right]$, p. 2).

Particularista, desde el momento en que su modelo es individual (y no sabemos hasta qué punto sólo idiolectal), y contradictoria, desde el momento en que, a pesar de hacer esta declaración, el traductor presenta su texto como la traducción andaluza - así se promocionó en los medios de comunicación y se vende todavía hoy este producto.

Por lo que toca a la ortografía sobre la que se conforma en el libro, Huan Porrah ensaya la siguiente justificación:

¿I por ké ehtá ehkrito kon ehta ortografía? Po porke la porfía a tento'e la ehkritura'el andalú buye en un prozezo bibo en buhkia dun akuerdo k'otabía no a yegao; porfía entre lah taramah de lah propuehtah d'ehkritura etimolóhika i lah propuehtah de trahkrizión ehnolinguíhtika. Azín k'el autó d'ehta traduzión al andalú a dezidío maneha de zuyo la orzión ortográfika ehnolinguíhtika yamá Normah ortográfikah pa la Trahkrizión del Andalú..., de la kuá eh zu prinzipá promotó ([And], p. 2).

Como vemos, en las dos citas anteriores Porrah se refiere a la ausencia de acuerdo normativo respecto de la escritura del andaluz. Sin embargo, como ya hemos apuntado, esa falta de acuerdo no trasciende fuera del reducido grupo de integrantes de la ZEA, pues no supone una demanda ni siquiera previsible a corto plazo dentro de la comunidad lingüística andaluza $y$, en este sentido, lo que el traductor plantea aquí es un falso problema, desde el momento en que no existe "porfía" alguna ${ }^{18}$ : la escritura en andaluz es sólo preocupación o desvelo de

17 A partir de ahora, utilizamos las abreviaturas entre corchetes para referirnos a las siguientes muestras del corpus: $[O]$ para el texto francés original; $[A n d]$ para la versión andaluza; [Esp1] para la traducción española de Bonifacio del Carril; [Esp2] para la traducción española de Sandra Caula; $[$ Mur $]$ para la versión murciana; y $[E x t]$ para la versión extremeña.

${ }_{18}$ A no ser que se refiera a los debates que se mantienen cada cierto tiempo en las reuniones de la "Huntah d'ehkritoreh" que convoca la ZEA. 
una minoría (pseudo)intelectual casi anecdótica en Andalucía. Por lo demás, no se encuentra en este habanteo apunte alguno sobre las decisiones metodológicas que guían la labor de traducción: el interés del autor recae en el resultado, no en el proceso.

ER PRINZIPITO Y LAS SOLUCIONES DE CONVERGENGIA Y DIVERGENCIA

En este apartado iremos desgranando desde una perspectiva traductológica cómo se configura la traducción "andaluza" de Er prinzipito en virtud de los movimientos de convergencia y de divergencia que son consustanciales a los procesos de traducción y que configuran las variantes basadas en el contacto en este tipo de texto ${ }^{19}$. Tales movimientos, en un proceso normal de traducción, son a veces conscientes y otras veces inconscientes (cf. Del Rey 2020), aunque en el caso de Er prinzipito la gran mayoría de las variantes de traducción es resultado de un proceso plenamente consciente de confrontación entre el resultado ¿andaluz? y los modelos que sirven de guía a la constitución del texto - un proceso, además, particularista de "un andaluz" que en lo fonético persigue fijar el propio uso lingüístico de Huan Porrah y en lo gramatical recoge variantes fuertemente estigmatizadas sociolingüística y diamésicamente.

Nuestra primera hipótesis de trabajo, al enfrentarnos con la traducción de Porrah, fue que el modelo exclusivo de [And] es una versión [Esp1], respecto de la que el traductor, de manera sistemática, buscaba las soluciones más divergentes posibles. Sin embargo, al hilo del análisis, descubrimos que Porrah no desconsidera $[O]$. Esto resulta evidente en casos como (1), donde la versión $[A n d]$ es la más cercana a $[O]$ de cuantas constituyen el corpus tenido en cuenta en este trabajo. No obstante, también notamos que cuando la versión de $[A n d]$ se acerca más a $[O]$ —es decir, revela resultados convergentes con $[O]$ - es, la mayoría de las veces, porque la traducción de Bonifacio del Carril ([Esp1]) evidencia una solución de divergencia, como se

${ }^{19}$ Los ejemplos que hemos seleccionado pertenecen a diferentes niveles de análisis lingüístico —ortográfico, léxico, morfológico, sintáctico y discursivo-, si bien hemos preferido no establecer subapartados para que destaque la linealidad de la argumentación que proponemos, desde la identificación de los modelos de Porrah hasta las decisiones de divergencia e inconsistencias más flagrantes de traducción. 
observa en (2), donde Porrah utiliza el mismo adjetivo que se lee en el original (exact). Se colige de ejemplos como éstos que $a$ ) para Porrah la convergencia con $[O]$ no plantea ningún problema, y que $b$ ) el propósito fundamental del traductor es la divergencia en cuanto a [Esp1]:

(1) a. O: Alors, faute de patience..., je griffonnai ce dessin-ci (p. 18).

b. And: Entoze, fartito de pazienzia..., lihero le garabateé ehte dibuho (p. 14)

c. Esp1: Entonces, impaciente..., garabateé este dibujo (p. 14).

d. Esp2: Entonces, irritado..., garabateé este dibujo (p. 14).

e. Ext: Altoncis, ya to encalmaítu con las priesas..., l'espaché esti dibuju (p. 21).

f. Mur: Antonces, agotá mi pacencia..., garabateé este debujo (p. 12).

(2) a. O: C'est exact!' Mais pourquoi veux-tu que tes moutons mangent les petits baobabs? (p. 26).

b. And: ¡Ezahto! Pero ¿por ké'hkiereh ke tuh borregoh ze koman loh baobáh xikitiyoh? (p. 22).

c. Esp1: ¡Es cierto! Pero ¿por qué quieres que tus corderos coman baobabs pequeños? (p. 22).

d. Esp2: iEs verdad!' Pero ¿por qué quieres que tus corderos se coman los baobabs pequeños? (p. 26).

e. Ext: iJustu! Peru ¿pa qué quieris tú que los tus borreguinus se jinquin a los baobabs chicus? (p. 32).

f. Mur. Equilicuá. Pero ¿poiqué chies que tus forreguicos se jalen a los baobás cuando sean menuicos? (p. 20).

Algunas veces, la convergencia con $[O]$ y paralela divergencia respecto de [Esp1] redunda en una transferencia a la vez que en una hipercaracterización ${ }^{20}$ en $[A n d]$, como se observa en (3), donde la perífrasis de relativo francesa, gramaticalizada, se acepta en la traducción andaluza, si bien el enunciado del TM demuestra una fuerza ilocutiva inexistente en $[O]$ y en las

${ }^{20}$ Según nuestra clasificación de fenómenos traductológicos que se deben a los tipos de variación que denominamos basada en el contacto y gradativa, la transferencia y la hipercaracterización suponen siempre una solución marcada en el TM (cf. Del Rey 2020), que en este caso es producto de una transposición - la construcción con perífrasis de relativo-y de una hipergradación - puesto que la perífrasis de relativo no es una solución marcada en la lengua de $[O]$ (ya que se trata de un esquema interrogativo gramaticalizado en francés; cf. DufTer 2008), mientras que sí lo es en [And]. 
otras versiones que se decantan por una traducción más aséptica enunciativamente:

(3) a. O: Mais... qu'est-ce que tu fais là? (p. 16).

b. And: Pero... ¿tú kéh lo ke hazeh porahkí? (p. 12).

c. Esp1: Pero... ¿qué haces aquí? (p. 12).

d. Esp2: Pero... ¿qué haces aquí? (p. 11).

e. Ext: Peru... ¿qué jacis tú p'aquí? (p. 20).

f. Mur: Pero... ¿qué haces tú aquí? (p. 10).

Sin embargo, si los resultados de $[A n d]$ fueran en todos los casos divergentes en lo que toca a [Esp1], no tendríamos base para afirmar que la traducción andaluza se elabora con la guía de la traducción española. Los ejemplos de identidad, como la que se produce en el nivel léxico en (4), demuestran que [Esp1] funciona como modelo directo de $[A n d]$; un caso, además, que refleja coincidencia única en el conjunto de traducciones. Coincidencia con la preferencia sintáctica de [Esp1] también es perceptible en el ejemplo (5), en que el término del sintagma preposicional está constituido por un infinitivo en $[A n d]$ — también en $[M u r]$, que evidenciaría, asimismo, el fenómeno de la identidad ${ }^{21}$ con [Esp1] - en lugar del sustantivo que se emplea en $[O]$ y en las otras versiones:

(4) a. O: Et la grande personne était bien contente de connaître un homme aussi raisonnable... (p. 15).

b. And: I la perzona mayó ze keaba mu kontenta de konozè a un ombre tan kabá (p. 11).

c. Esp1: Y la persona mayor se quedaba muy satisfecha de haber conocido a un hombre tan razonable (p. 11).

d. Esp2: Y el adulto se sentía muy contento de conocer a un hombre tan razonable (p. 10).

e. Ext: Y la presona mayol bien que s'alegraba d'habel jechu conocencia d'un jombri tan razonabli (p. 17).

f. Mur. Y la presona mallor se sintía mu contentica d'haber conocío un hombre tan razonable (p. 9).

(5) a. O: Il me répondit après un silence méditatif (p. 20).

b. And: Dihpuéh'e kabilal-lo kayaito, me rehpondió (p. 16).

c. Esp1: Después de meditar en silencio, respondió (p. 16).

${ }^{21}$ Utilizamos la categoría de identidad para referirnos a fenómenos de convergencia con el TF que no producen soluciones marcadas en el TM (cf. DeL Rey 2018). 
d. Esp2: Me respondió, tras un silencio meditativo (p. 18).

e. Ext: Me respondió dispués d'un silenciu meditativu (p. 25).

f. Mur: Dimpués e meitar en silencio me rispondió (p. 14).

Es en estos casos, en que los resultados son producto de la interferencia negativa en el TM respecto del modelo [Esp1], cuando podemos aventurar la hipótesis de que los fenómenos de identidad en $[A n d]$ son consecuencia de un proceder inconsciente del traductor, ya que, por regla general, Porrah busca deliberadamente la divergencia en lo que toca a la traducción castellana más extendida. Claro que la hipercaracterización conscientemente perseguida por el traductor en todas las variantes seleccionadas supone una acción de manipulación del TM, que no contradice, en el plano cognitivo, la asunción inconsciente de formas presentes en [Esp1] y ausentes de [O]. Así lo volvemos a comprobar en (6), donde el conector que aparece en la traducción de Bonifacio del Carril, en vez de la relación yuxtapositiva original, se respeta en la versión andaluza, claro que con cambio de adscripción variacional —cambio no determinable, por cierto, en [Mur], traducción en la que, sin embargo, vuelve a hacerse evidente la dependencia respecto de $[\operatorname{Esp1]}$-:

(6) a. O: "Est-ce qu'il collectionne les papillons?" Elles vous demandent: "Quel âge a-t-il?" (p. 23).

b. And: “¿Le guhta rehunta palomitah?” D’otro bizo, zí ke zoh preguntan: “¿Ké edá tiene?” (p. 19).

c. Esp1: “¿Colecciona mariposas?”. En cambio, os preguntan: “¿Qué edad tiene?" (p. 19).

d. Esp2: “¿Colecciona mariposas?”. Preguntan: “¿Qué edad tiene?" (p. 22).

e. Ext: “¿Arrejunta mariposas?”. Vus preguntarán: “¿Cuala es la su edá?” (p. 29).

f. Mur: “¿Arrejunta palometas?”. Al revés, priguntan: “¿Qué tiempo tie?” (p. 17).

Demostrado, pues, que [And] parte de [O] y de [Esp1] para enhebrar su texto, veremos ahora cómo, efectivamente, cuando [Esp1] converge con [O], prácticamente en todos los casos en los que le es posible ${ }^{22}$, Porrah introduce una selección de

${ }^{22}$ Para que sea posible, es necesario que la forma o la función que se somete a análisis pueda interpretarse como variable, es decir, como suscep- 
variantes divergentes de ambos modelos. Dicha divergencia puede manifestarse en un cambio del orden de los constituyentes de la oración, como ocurre con el sintagma nominal en función de complemento de tiempo en (7), en un contexto en el que el mantenimiento después del verbo regente no supondría siquiera un problema para la caracterización diatópica del segmento, o en (8), donde el sujeto pronominal de $[O]$ y de [Esp1] se transforma en una construcción preposicional en $[A n d]$ y donde la oración de relativo es sustituida por un gerundio, variante esta que quizás habría sido más normal, en el sentido coseriano, en español, sin que la construcción relativa suponga, sin embargo, una construcción marcada por transposición respecto del original francés, ya que gerundio y oraciones de relativo funcionan históricamente como variantes lingüísticas intercambiables en numerosos contextos (cf. Del Rey 2019):

(7) a. O: Lorsque j'avais six ans j'ai vu, une fois... (p. 13).

b. And: Una beh, kuando yo tenía zeih z'añiyoh bi... (p. 9).

c. Esp1: Cuando yo tenía seis años vi una vez... (p. 9).

(8) a. O: Ça représentait un serpent boa qui avalait un fauve (p. 13).

b. And: En é ze figuraba a una bixa boa tragándoze una fiera (p. 9).

c. Esp1: Representaba una serpiente boa que se tragaba a una fiera (p. 9).

A veces, la divergencia a la fuerza que evocamos en el título de este trabajo lleva a Porrah a distorsionar el sentido del original con tal de no utilizar la solución coincidente con $[O]$ y con [Esp1]. Es lo que ocurre en (9), donde [And] presenta una forma de futuro sintética que aporta al enunciado un significado epistémico del que carecen tanto el original como la traducción de Bonifacio del Carril y la traducción americana de Sandra Caula:

(9) a. O: jusqu'à une panne dans le désert du Sahara, il y $a$ six ans (p. 15).

tible de ser expresada a partir de, al menos, dos variantes. En el caso de las invariables formales o funcionales, no sería posible hablar de convergencia o divergencia, en cuanto que dichos fenómenos se basan en la posibilidad, consciente o inconsciente, que tiene el traductor de usar determinadas variantes de lengua (cf. Del Rey 2018, p. 24, n. 10). 
b. And: ahta ke tube una abería en er dezierto der Záhara, hará zeih z'añoh (p. 11).

c. Esp1: hasta que tuve una panne en el desierto de Sahara, hace seis años (p. 11).

d. Esp2: hasta que tuve una avería en el desierto del Sahara, hace seis años (p. 10).

Asimismo, la tendencia del traductor de $[A n d]$ a la divergencia respecto de los modelos francés y castellano redunda en numerosas ocasiones en una hipercaracterización falseadora de la realidad lingüística andaluza. Así, en (10), la coincidencia semántica entre el original $(10 a)$ y las traducciones castellanas $(10 c-d)$, esto es, parler = 'hablar', no se refleja en la traducción de Porrah, que introduce, con el ánimo de divergir de [Esp1], el verbo charlar en un contexto donde resulta absolutamente anómalo. En efecto, en este caso hablar cuadra a la perfección, como traducción de parler, con la capacidad de emitir sonidos después de un esfuerzo físico o psíquico considerable. Pero xahlà 'charlar' no es un verbo que, ni en andaluz ni en cualquier otra variedad hispánica — hasta donde nuestro conocimiento alcanza-, pueda asumir ese valor semántico, sino que se refiere al hecho de conversar con otro(s), es decir, no responde a una capacidad física o intelectual en bruto, sino a un hecho de comunicación para el que es necesario hablar, verbo que sí puede referirse a dicha capacidad. En otras palabras, uno es capaz o incapaz de hablar, pero no de charlar, a menos que se especifique un complemento: incapaz de charlar con ellos. Aquí, sin embargo, Porrah no usa xahlà en el sentido de 'conversar con', sino en el de 'hablar', y en consecuencia aplica al verbo una acepción — de nuevo, hasta donde nuestro conocimiento alcanza - inexistente en las hablas andaluzas:

(10) a. O: Quand je réussis enfin à parler, je lui dis... (p. 16).

b. And: Ar remate, kuando fui ehkapá'e xahlà, le dihe... (p. 12).

c. Esp1: Cuando al fin logré hablar, le dije... (p. 12).

d. Esp2: Cuando al fin logré hablar, le dije... (p. 11).

En ocasiones, la siempre buscada divergencia respecto de [Esp1] por parte de [And] motiva, como vimos, la convergencia con $[O]$, pero, en algunos casos, se produce, de nuevo, una hipercaracterización que no se halla en ninguna de las otras traducciones que conforman nuestro corpus, que introducen 
en este mismo contexto soluciones no marcadas. En el ejemplo (11), la presencia del pronombre sujeto en $[A n d]$, sin duda motivado por el modelo -donde, sin embargo, el pronombre es obligatorio-, dota el enunciado de una fuerza ilocutiva mayor que la del texto original. Este tipo de hipercaracterización se relaciona con la variación gradativa que es necesario tener también en cuenta en los estudios traductológicos (cf. Del Rey 2020, y supra, n. 20).

(11) a. O: Je fis remarquer au petit prince que les baobabs ne sont pas des arbustes, mais des arbres grands comme des églises (p. 26).

b. And: Yo l'ehpliké ar prinzipito ke loh baobáh no zon arbuhtoh, zinó árboleh de grande komo igleziah (p. 22).

c. Esp1: Hice notar al principito que los baobabs no son arbustos, sino árboles grandes como iglesias (p. 22).

d. Esp2: Le hice notar que los baobabs no son arbustos, sino árboles grandes como iglesias (p. 25).

e. Ext: Jici que se coscasi al prencipinu de que los baobabs nu son arbustus, sinu árbulis grandis comu ilesias (p. 31).

f. Mur. L'asieguré ar principico que los baobás no son arbustos, sino árboles mu jrandes de la jrandaria de las ilesias (p. 19).

Otro efecto de la divergencia respecto de $[E s p 1]$ en $[A n d]$ es la convergencia con $[O]$ que causa transposición, es decir, el uso de una forma anormal y, según los casos, semánticamente inadecuada, tal y como también comentamos a propósito de (10). En (12), la traducción no marcada del original mettre equivale al verbo español poner. La versión extremeña evidencia un uso diatópicamente marcado pero que respeta el sentido original del verbo correspondiente en el TF. La solución de Porrah, sin embargo, converge formalmente con $[O]$ (mettre - meter), lo que distorsiona el sentido del original e incurre en una incongruencia semántica, pues la imagen que se describe se refiere a una superposición de entidades y no a la inclusión de unas en otras. De nuevo, la divergencia de [Esp1] descansa en una manipulación indeseable del texto original:

(12) a. O: Il faudrait les mettre les uns sur les autres... (p. 26).

b. And: Abría ke metel-loh uno enzima'el otro... (p. 22).

c. Esp1: Habría que ponerlos unos sobre otros... (p. 22).

d. Esp2: Habría que ponerlos unos sobre otros... (p. 25). 
e. Ext: Serie mestel sostribalus unus polcima d'otrus... (p. 31). f. Mur. Habiá que ponerlos uno ancimica d'otro... (p. 20).

Las divergencias de [And] respecto de [Esp1], con todo, no siempre producen resultados recriminables; al contrario, la divergencia que busca Porrah a veces propicia mejoras estilísticas en comparación con las soluciones de [Esp1], lo que es evidente cuando la convergencia de [Esp1] con $[O]$ da como resultado formas que podríamos considerar marcadas, como vimos en $(9 b-c)$ a propósito de la diferencia léxica abería - panne, respectivamente, y como vemos en (13): el nexo final a fin de que puede interpretarse como forma marcada por transposición en cuanto al nexo más normal - de nuevo, en el sentido coseriano- para que, por el que se decanta [Esp2]. El uso del gerundio en $[A n d]$, si bien responde a una solución marcada desde el punto de vista de la variación diasistemática - el dequeísmo es un fenómeno diastrática y diafásicamente marcado como bajo-, no lo es tal desde la perspectiva de la variación basada en el contacto, ya que el uso del verbo procurar en gerundio, dado el sentido proyectivo que caracteriza al verbo, en este contexto es perfectamente apto como traducción de una oración subordinada final. Asimismo, la identidad sintáctica de [Esp1], que respeta [Mur] en (14), se elimina en [And], como en [Esp2] y $[E x t]$, para producir un resultado más normal en el TM, menos dependiente del modelo francés:

(13) a. $O$ : J'ai alors dessiné l'intérieur du serpent boa, afin que les grandes personnes puissent comprendre (p. 14).

b. And: Kohí entoze i dibuhé el interió de la bixa boa, perkurando de ke lah perzonah mayoreh lo entendieran (p. 10).

c. Esp1: Dibujé entonces el interior de la serpiente boa a fin de que las personas mayores pudiesen comprender (p. 10).

d. Esp2: Dibujé entonces el interior de la serpiente boa, para que los adultos pudieran comprender (p. 8).

(14) $a$. $O$ : Il était une fois un petit prince qui habitait une planète à peine plus grande que lui, et qui avait besoin d'un ami... (p. 24).

b. And: Éraze una beh un prinzipito k'abitaba en un planeta no munxo mah grande ke é i ke néhitaba un amigo... (p. 20).

c. Esp1: Había una vez un principito que habitaba un planeta apenas más grande que él y que tenía necesidad de un amigo... (p. 20). 
d. Esp2: Había una vez un principito que vivía en un planeta apenas más grande que él, y que necesitaba un amigo... (p. 23).

e. Ext: Érasi una ves un prencipinu que vivía en un planeta apeninas más grandi qu'él, y que nesecitaba un amigu... (p. 29).

f. Mur: Había una vez un principico que vevía en un praneta una miaja más jrande que él y que teniba nesecidá d'un amigo... (p. 18).

A veces puede percibirse en [And] una tensión entre los dos modelos, tensión en la que prima la divergencia respecto de [Esp1], como creemos haber demostrado, y que condiciona en todo momento, probablemente de manera inconsciente, las soluciones que se realizan en la traducción de Porrah. Así, en (15), si por un lado la explicitación del pronombre demostrativo sujeto ezo revela un resultado convergente con $[O]$ que distancia a $[A n d]$ de la traducción hecha por Del Carril, por otro lado, Porrah acepta negligentemente la solución de identidad de [Esp1] en el segmento que existe por qu'on existe. En efecto, la traducción de Bonifacio del Carril no es apropiada porque, en su formulación, el sujeto del verbo se corresponde lógicamente con el objeto del infinitivo, esto es, un borrego, distorsión lamentable en lo que toca al sentido del original, en el que la existencia se refiere en general a 'todo ser humano con la capacidad de querer un borrego'. Porrah converge con tal distorsión, lo que llama poderosamente la atención en virtud de su inclinación constante de divergencia a propósito de [Esp1]:

(15) a. O: Quand on veut un mouton, c'est la preuve qu'on existe (p. 24).

b. And: Er kerè un borrego ezo eh prueba de k'ezihte (p. 20).

c. Esp1: Querer un cordero es prueba de que existe (p. 20).

Asimismo, el ejemplo (16) muestra cómo dicha tensión responde a un estímulo a la vez consciente de divergencia y presumiblemente inconsciente de convergencia en relación con [Esp1]. La oración hendida ${ }^{23}$ del francés utiliza el verbo copulativo en presente, mientras que la traducción de Bonifacio del

${ }^{23}$ Sobre las oraciones hendidas o perífrasis de relativo como estrategia de intensificación, cf. Gutiérrez Ordóñez 1986, Roggia 2009, Dufter 2008 y las referencias en Del Rey 2015a. 
Carril opta por la forma en perfecto, que mantiene $[A n d]$. El nexo relativo que continúa al verbo copulativo es, sin embargo, divergente en Porrah, quien pretende acercarse a la forma del original al hacer explícito el pronombre que en lugar del adverbio relativo como:

(16) a. O: Et c'est ainsi que je fis la connaissance du petit prince (p. 19).

b. And: I azín fue la manera en ke konozí ar prinzipito (p. 15).

c. Esp1: Y así fue como conocí al principito (p. 15).

La mayor parte de los ejemplos aducidos hasta este momento, y otros muchos que por cuestión de espacio debemos obviar, permite afirmar que, si bien Porrah tiene en cuenta el texto original de Antoine Saint-Exupéry, su versión no es una traducción interlingüistica de [O], sino una intralingüisitica de [Esp1]. $\mathrm{Su}$ texto consiste en un juego o pasatiempo en virtud del cual se seleccionan variantes diasistemáticas pertenecientes al ámbito de la inmediatez comunicativa ${ }^{24}$ (cf. "Traducción, normalización y estandarización lingüística”), para introducir, siempre que tiene ocasión, fenómenos marcados ${ }^{25}$ diatópicamente, no sólo en el nivel fonético, como se desprende passim de su propuesta ortográfica, sino también en el nivel léxico y, en menor

${ }^{24}$ Es cierto que, en la mayoría de las ocasiones, el deseo de divergencia de $[A n d]$ respecto de [Esp1] se resuelve en un movimiento hacia el ámbito de la inmediatez, generalmente porque las variantes que se encuentran en [Esp1] pertenecen a la variedad estándar. Cuando en la traducción española de Bonifacio del Carril se encuentra alguna variante propia del ámbito de la distancia comunicativa, Porrah se conforma, frecuentemente, con divergir de [Esp1] moviéndose en el continuum hacia la zona estándar (cf. supra, Figura 1). Es lo que ocurre en el siguiente ejemplo (A), donde un esquema típico de los discursos concepcionalmente distantes, la construcción pasiva analítica, que es en [Esp1] producto de la convergencia con el texto original, se resuelve en una construcción de pasiva refleja, en español susceptible de emplearse en todo tipo de manifestaciones lingüísticas a lo largo del continuum, y configura, por lo tanto, una variante estándar: (A) $a$. [O]: "Cet astéroïde n'a été aperçu qu'une fois au télescope, en 1909, par un astronome turc" (p. 23); b. [And]: "Ehte ahteroide z'a bihto namáh k’una beh kon er telehkopio, en 1909, por un ahtrónomo turko" (p. 19); c. [Esp1]: "Este asteroide sólo ha sido visto una vez con el telescopio, en 1909, por un astrónomo turco" (p. 19).

${ }^{25}$ En ocasiones, sin embargo, se emplean formas marcadas en el ámbito de la distancia comunicativa pero que, disfrazadas ortográficamente, crean una especie de paradoja concepcional, como en "ozerbó kabarmente" ([And], p. 22), tal y como advierte también MaRín (2019, p. 87). 
medida, también en el sintáctico. De este modo, se observa en (18) cómo Porrah utiliza la voz chorla marcada en el ámbito de la inmediatez comunicativa en los tres niveles de variación diasistemática en vez de la voz no marcada cabeza en [Esp1] como traducción del francés tête (17). Igualmente, se emplea la combinación marcada diatópicamente (cf. Narbona Jiménez et al. 2003, p. 24) mah na (más nada) como solución sintáctica preferida al sólo de la traducción española de Del Carril (18):

(17) a. $O$ : Et un jour il me conseilla de m'appliquer à réussir un beau dessin, pour bien faire entrer ça dans la tête des enfants de chez moi (p. 28).

b. And: I un día m'engrió a ehmerarme en apañà un bonito dibuho, pa metérzelo bien en la xohla a loh niñoh de mi tierra (p. 24).

c. Esp1: Y un día me aconsejó que me aplicara a lograr un hermoso dibujo, para que entrara bien en la cabeza de los niños de mi tierra (p. 24).

(18) a. O: et je n'avais rien appris à dessiner, saufles boas fermés et les boas ouverts (p. 16).

b. And: no abía aprendío a dibuhà mah na ke boah zerráh i boah abiertah (p. 12).

c. Esp1: sólo había aprendido a dibujar las boas cerradas y las boas abiertas (p. 12).

Pero las variantes marcadas de $[A n d]$ no se explican, en la mayoría de los casos, en virtud de los condicionamientos diatópicos que las determinan, como pretende el autor de esta "traducción", sino en función de factores relacionados con las dimensiones de variación diastrática y diafásica. Si dejamos de lado los rasgos de caracterización fonética en los que se basa la ortografía amparada por la ZEA, que son los más significativos de la hipercaracterización caricaturesca de la variedad que nos presenta Porrah, observamos que, de entre los rasgos diatópicos identificados en $[A n d]$, se seleccionan preferentemente aquellos que, a su vez ${ }^{26}$, están marcados diastráticamente como bajos. Tal es el caso del aparente uso de la tercera persona del

${ }^{26}$ Recordemos que, según el modelo de la cadena de variedades que parte de Coseriu (1980), lo diatópicamente marcado puede funcionar como diastráticamente marcado e, igualmente, lo diastráticamente marcado puede funcionar como diafásicamente marcado, pero no a la inversa (cf. Koch y OesterReicher 2007 [1990], pp. 37-40). 
verbo haber en los tiempos compuestos para la expresión de la primera persona verbal (cf. Mondéjar 1994, pp. 125 y 324) en el ejemplo (19), que, por lo que toca a la variación basada en el contacto, evidencia asimismo una solución de transposición respecto de $[O]$, de nuevo, para evitar la convergencia con [Esp1]. Lo mismo cabe decir del uso del auxiliar ser en los tiempos compuestos (20), un fenómeno minoritario en andaluz y muy marcado en el nivel diastrático al igual que sucede en las áreas americanas donde se documenta este uso (cf. Méndez García de Paredes 2011). Estos ejemplos del paradigma verbal que inciden en soluciones desprestigiadas y casi anecdóticas en el andaluz representan, de este modo, variantes hipercaracterizadas de la variedad andaluza que en ningún caso podrían proponerse como estándar de una variedad, pues son ajenas a la mayoría de los hablantes y desconocidas para una gran parte de la población andaluza:

(19) a. O: J'ai connu une planète, habitée par un paresseux (p. 28). b. And: Yo a konozio un planeta, abitao por un floho (p. 24). c. Esp1: Conocí un planeta habitado por un perezoso (p. 24).

(20) a. O: J'aurais aimé commencer cette histoire à la façon des contes de fées. J'aurais aimé dire... (p. 24).

$b$. And: A mí me fuera guhtao d'empezà ehta ihtoria a la manera'e loh kuentoh de adah. Me fuera guhtao'e dezì... (p. 20).

c. Esp1: Hubiera deseado comenzar esta historia a la manera de los cuentos de hadas. Hubiera deseado decir... (p. 20).

Son las soluciones marcadas diafásicamente como bajas, sin embargo, las que sirven con más frecuencia al autor de [And] para (hiper) caracterizar la variedad a la que pretende dotar de autonomía y tradición escrita. En mayor medida es en el nivel léxico donde mejor se aprecia el interés de Porrah por utilizar este tipo de variantes. Es decir, su propuesta se basa en la selección de voces que se restringen a situaciones de uso informal, voces, éstas sí, por lo general, comunes no sólo a una mayoría de andaluces, sino también a una mayoría de hispanohablantes, o al menos de hablantes del español peninsular, si bien comunes sólo a su variedad hablada. Esto es, en efecto, lo que olvida, o quiere olvidar, Porrah: que el andaluz es un conjunto de hablas, y que lo que a ellas pertenece como más característico se localiza en el ámbito de la inmediatez comunicativa. Así se puede apreciar en los ejemplos (21) y (22), concretamente en 
el contraste de voces coordinadas entre $[E s p 1]$ y [And]: Bonifacio del Carril utiliza formas no marcadas ${ }^{27}$ como soluciones de identidad en cuanto a $[O]$, mientras que Porrah demuestra una vez más aquí su deseo de divergencia ${ }^{28}$ por medio del uso de variantes marcadas diafásicamente como bajas, pero ninguna de ellas exclusiva del andaluz — chaval, perdido, guarnido, desmayado, espantado, alobado son, en efecto, con sus diversas realizaciones fonéticas, palabras generales al español. En la Tabla 1 ofrecemos algunas correspondencias entre $[E s p 1]$ y $[A n d]$ en las que puede comprobarse que la selección léxica de Bonifacio del Carril se mueve entre la zona central y derecha del esquema (Figura 1, supra), mientras que la de Porrah se restringe a la izquierda, para confinar de esta manera la variedad que se propone legitimar a sólo el ámbito de la inmediatez comunicativa:

(21) a. O: Or mon petit bonhomme ne me semblait ni égaré, ni mort de fatigue, ni mort de faim, ni mort de soif, ni mort de peur (p. 16).

b. And: Kon to i kon ezo, er xabaliyo no me ze hazía ni perdio, ni guahnío, ni ehmayao, ni kon gana'e agua, ni ehpantao (p. 12).

c. Esp1: Además, el hombrecito no me parecía ni extraviado, ni muerto de fatiga, ni muerto de hambre, ni muerto de sed, ni muerto de miedo (p. 12).

(22) a. O: Et je fus stupéfait d'entendre le petit bonhomme me répondre... (p. 18).

b. And: I me keé alobao al ehkuxa k'er xabá me rehpondía... (p. 12).

c. Esp1: Quedé estupefacto cuando oí al hombrecito que me respondía... (p. 14).

27 Salvo los adjetivos extraviado y estupefacto, que podrían considerarse formas léxicas marcadas, como pertenecientes al ámbito de la distancia comunicativa.

${ }^{28}$ Obsesivo deseo de divergencia, podríamos decir, pues se percibe incluso en la sustitución del sintagma muerto de sed (más verosímil en las situaciones de la inmediatez comunicativa en las que se basa Porrah para su selección de variantes) por con gana'e agua (con ganas de agua), variante inadecuada contextualmente desde el punto de vista pragmático. En general, vemos en este ejemplo cómo la recurrencia estilística mort de $X$ con la que se inscriben unidades fraseológicas elativas propias del discurso repetido en $[O]$ y se mantienen en $[E s p 1]$ se elimina en [And] sin más motivo que introducir "a la fuerza" determinados tópicos léxicos, tenidos por andaluces, que pululan de inventario en inventario: guarni $(d) o$, (d)esmaya $(d) o$, etc., sin que se haya comprobado fehacientemente que sean tales. 
TABLA 1

Confrontación de algunas variantes léxicas entre [Esp1] y [And]

\begin{tabular}{ll}
\hline$[$ Esp1] & {$[$ And $]$} \\
\hline pequeño & chico \\
salto & brinko \\
enfermo & paxuxo \\
hermosa & xula \\
talla & hexura \\
nos burlamos & moh caxondeamoh \\
infestado & minao \\
golpeado & xihporroteao \\
con... mal humor & enritaete \\
\hline
\end{tabular}

También aparecen en $[A n d]$ variantes marcadas diafásicamente como bajas en el terreno sintáctico, pero de nuevo se engañaría el lector si pensara que tales variantes son exclusivas del andaluz, ya que se trata de fenómenos por demás frecuentes en prácticamente todas las variedades hispánicas. Así puede decirse de la construcción despronominalizada (cf. Lope Blanch 1987 [1983]) o de pronombre reasuntivo (cf. Fernández Soriano 1995) que aparece en la versión de Porrah (23b), donde el pronombre relativo del original francés y de la traducción de Bonifacio del Carril se convierte en mero conector entre la oración principal y la subordinada, mientras que la referencia anafórica se traslada al pronombre átono $l o$, procedimiento este muy habitual en los discursos no planificados de cualquier variedad hispánica. También típicos de los discursos no planificados en español no exclusivamente meridional son los esquemas que la gramática tradicional definiría como anacolutos: ejemplo de ello es (24), donde se produce una suerte de reinicio que motiva la reestructuración de los argumentos del verbo, en tanto que el sujeto lógico codificado en primer lugar por medio de un sintagma preposicional en función de dativo iudicans se convierte después de la oración de relativo en el sujeto gramatical. De esta manera, la progresión sintáctica del enunciado cambia en el curso de la formulación lingüística del personaje: 
(23) a. O: Quand j'en rencontrais une qui me paraissait un peu lucide, je faisais l'expérience sur elle de mon dessin numéro 1 que j'ai toujours conservé (p. 15).

b. And: Kuando a rezurtao de hayarme kon argien ke me'hkería pareze de tene arguniyah luzeh, le hazía la prueba de mi dibuho número 1, k'otabía lo guardo (p. 11).

c. Esp1: Cuando encontré alguna que me pareció un poco lúcida, hice la experiencia de mi dibujo número 1, que siempre he conservado (p. 11).

(24) a. O: Mais, bien sûr, nous qui comprenons la vie, nous nous moquons bien des numéros! (p. 24).

b. And: Pero, klaro, pa nohotroh k'entendemoh la bía, moh kaxondeamoh de loh númeroh (p. 20).

c. Esp1: Pero, claro está, nosotros que comprendemos la vida, nos burlamos de los números (p. 20).

Igualmente, $[$ And $]$ recurre a la evocación de estructuras prosódicas típicas de la oralidad concepcional para construir los diálogos $^{29}$. De nuevo, estrategias pragmáticas como la de (25) no son exclusivas del andaluz, sino comunes a la mayoría de los hablantes del español peninsular. En el ejemplo, la escisión del enunciado en dos grupos entonativos diferenciados (cf. Narbona 2015, p. 114) sirve para realzar informativamente el segmento sintáctico que queda en la periferia derecha del enunciado. Se trata, así, de una estrategia de hipergradación (cf. Del Rey 2020) que dota la versión de Porrah de una mayor fuerza ilocutiva que la que se desprende de [O] o de [Esp1]:

(25) a. $O$ : Tu viens donc d'une autre planète? (p. 20).

b. And: ¿Entoze tú ke bieneh, d'otro planeta? (p. 16).

c. Esp1: ¿Vienes, pues, de otro planeta? (p. 16).

Al seleccionar variantes marcadas diastrática y/o diatópicamente como bajas comunes a los hablantes del español estándar peninsular, Porrah comete dos errores vitandos si se quiere obtener una idea cabal del español hablado en Andalucía: $a$ ) se ali-

${ }^{29}$ Se puede alabar a Porrah, eso sí, una fina sensibilidad para la plasmación por escrito de estrategias de verosimilitud conversacional (cf. NARBONA 2001; Bustos Tovar 2017; López Serena 2007; Del Rey 2011), si bien, por la hipercaracterización del texto, la mayoría de las veces las estrategias coloquiales que evoca no son adecuadas al tipo de diálogo que construye en el original Antoine de Saint- Exupéry. 
nea con la vieja tradición descriptiva del andaluz según la cual los fenómenos vulgares o las estrategias de conversación informales caracterizan diatópicamente el habla de una región ${ }^{30}, \mathrm{y} b$ ) hace pasar por andaluzas — disfraza ortográficamente de andaluzasformas no exclusivas del español hablado en el sur de España. Así pues, el intento de estandarización de Porrah no se basa solamente en presupuestos erróneos, sino también inciertos.

Para crear una ficción lingüística andaluza, Porrah juega al extrañamiento de poner por escrito variantes pertenecientes al ámbito de la inmediatez comunicativa tradicionalmente excluidas de la escritura en español. Pretende de esta forma demostrar que el andaluz es una realidad lingüística diferenciada del español estándar, divergente ${ }^{31}$ en todo, una realidad con personalidad histórica e idiomática. Sin embargo, (muy) poco de lo que hay en Er prinzipito es auténtica y exclusivamente anda$\mathrm{luz}^{32}$, pese a lo que incite a pensar la ortografía. Para Porrah, con todo, el fin justifica los medios, de ahí que no tenga reparos en ofrecer una hipercaracterización en muchos casos falseadora de la realidad lingüística andaluza. Tal es el caso del participio femenino del tiempo compuesto que aparece en (26), difícilmente verosímil como rasgo morfológico típico andaluz, o la forma de subjuntivo irregular con vibrante en vez de semivocal, según lo que se desprende de la selección ortográfica de los ejemplos de (27). Tampoco es verosímil como nexo subordinante el pa cuando + indicativo del ejemplo (28), que más bien responde a esa necesidad de extrañamiento que quiere conferir Porrah a su texto, por contraposición a la solución del español estándar:

${ }^{30}$ Basta recordar el proceder tradicional de la dialectología y el proceso de selección de los informantes de los atlas lingüísticos como el ALEA (analfabetas pertenecientes a zonas rurales que apenas han tenido contacto con la norma idiomática de prestigio). Ello se deja traslucir en la visión de los andaluces y de Andalucía como tierra de incultos, presente en el tópico "qué mal se habla en Andalucía”, generalizado tanto dentro como fuera de la comunidad autónoma.

31 Sobre la pertenencia del andaluz a una comunidad de habla dialectal divergente en el sentido de Milroy (1992, p. 55-60), cf. Villena Ponsoda (2008a, p. 378) y MARÍn (2019, p. 91).

32 Respecto de los fenómenos que afectan a la pronunciación andaluza, Narbona et al. (2003, p. 149) afirman que "no existe ningún rasgo exclusivo del andaluz, puesto que casi todos los que sostienen esa sensación de diferenciación se encuentran también en otras modalidades del español peninsular o en el canario y el español de América”. 
(26) And: ¡D’abel-lo dihfrutao é, huera podía armirà no kuarentikuatro puehtah de zó namah, zino zetentidóh u lo mihmo zien (p. 38).

(27) And: ¿I ke'h lo kai ke hazè pa ke ze karga er zombrero? (p. 43) / Ke trarga unoh peñohkoh (p. 55); ¡Entonze será marabiyozo kuando m’ arga domehtikao! (p. 69).

(28) And: Pa kuando er mihterio eh dehmaziao imprezionante, no ai'hkien puea dezobedezè (p. 12).

\section{Conclusiones}

En este artículo hemos querido dejar constancia, de manera razonada y crítica, de cómo el propósito que guía una (supuesta) traducción andaluza de El principito no es otro que el de divergir de las soluciones estándares o distantes (cf. supra, Figura 1) del español (fundamentalmente, peninsular, pero no sólo) con el fin de producir un efecto de extrañamiento que sirva para justificar la personalidad e individualidad lingüística del andaluz. En la práctica, ese efecto se basa, simplemente, en la selección de variantes pertenecientes al ámbito de la inmediatez comunicativa. La intención de Porrah no es otra que evitar a toda costa - aunque, como hemos demostrado, no siempre lo consigue - utilizar variantes estándares peninsulares o propias de la distancia comunicativa — variantes que, sin embargo, sí se encuentran en el original francés, lo que, también desde el punto de vista traductológico, invita a una reflexión sobre si $\mathrm{Er}$ prinzipito puede calificarse propiamente de traducción.

Para conseguirlo, lo más sencillo era recurrir a la traducción española más difundida ([Esp1]) y elaborar un texto por oposición a ella. Hemos podido comprobar cómo la búsqueda de la divergencia a la fuerza respecto de la traducción española se convierte en reto personal para Porrah. La consecuencia de ello es la hipercaracterización del andaluz, al que se le atribuyen como típicos rasgos no exclusivos de las variedades meridionales pero que parecen andaluces porque están disfrazados de una ortografía que evoca fenómenos fonéticos marcados diatópicamente y diastrática y diafásicamente como bajos. En contradicción con los propios intereses del autor, la tentativa de Porrah confirma - si bien no había necesidad de confirmación alguna - que el andaluz es una modalidad de habla. En 
su tendencia obsesiva por seleccionar, siempre que le es posible, rasgos concepcionalmente inmediatos, dinamita el interés de la Zoziedá pal Ehtudio'el Andalú (ZEA) por dignificar la(s) variedad(es) lingüística(s) de Andalucía. La causa de tal contradicción no es otra, en nuestra opinión, que la ignorancia del funcionamiento histórico de las lenguas o de su espacio variacional. Confinando el andaluz al ámbito de la inmediatez comunicativa, lo que consigue es negar al andaluz un espacio variacional propio. Y se lo niega, precisamente, porque el "traductor" no transige en aceptar que el espacio variacional del andaluz es común al del español peninsular.

La propuesta de un sistema de escritura particular para una determinada variedad lingüística que no dispone de él es uno de los pasos clave, quizás el más importante, de los procesos de estandarización (cf. Cheshire \& Stein 1997). Er prinzipito debe entenderse, pues, como un intento de estandarización del andaluz que satisface las reivindicaciones de la ZEA. Este intento de estandarización es, sin embargo, teóricamente inviable, puesto que se basa no sólo en rasgos diatópicamente marcados sino, sobre todo, en rasgos diastrática y diafásicamente marcados como bajos. Tal como vimos en el apartado "Traducción, normalización...", lo estándar se identifica con lo no marcado, o en todo caso con lo marcado en el ámbito de la distancia comunicativa -ésta es la visión tradicional, también presente en Koch y Oesterreicher 2007 [1990]; cf. Del Rey 2021—, pero nunca con lo marcado en el ámbito de la inmediatez. La proliferación de rasgos propios de este ámbito en $[A n d]$ es consecuencia del interés constante del autor por alejarse en la mayor medida posible en cada caso del lado central y derecho del esquema en la cadena de variedades (cf., de nuevo, Figura 1) para evitar la convergencia con [Esp1]. La traducción de Bonifacio del Carril representa la norma de un español estándar ${ }^{33}$ que funciona como variedad antagonista y fuerza coercitiva, idea que no comparte la gran mayoría de los andaluces, de ahí el revuelo mediático que originó la aparición de esta "traducción".

Para concluir, traemos a colación de nuestros argumentos finales la siguiente cita de Johannes Kabatek (2018), muy apropiada para la discusión del problema de la estandarización lin-

${ }^{33} \mathrm{Y}$ ello a pesar de que tal traducción no haya sido escrita por un hablante peninsular, como vimos en el apartado "Las traducciones de $L e$ petit prince...". 
güística al que estamos aludiendo. En su texto, el romanista alemán se refiere a una traducción voseante de los sonetos de Shakespeare que apareció hace unos años en Argentina:

Si la autora tradujera "duermes", traduciría a una variedad que para ella solo tiene connotación escrita pero no hablada. La forma voseante es la forma no marcada, no expresa ya argentinidad ni suena a arrabalero: se ve dignificada y forma parte de una posibilidad pluricéntrica de la lengua española cuyo pluricentrismo no rehúye los textos escritos elaborados. Podrían objetar algunos que esto es realmente un simple "experimento", una demostración tal como lo fue el famoso capítulo del Quijote en "Spanglish" presentado hace años por Ilan Stavans. Pero aquí es diferente: Stavans juega con la dignificación mediante traducción, pero lo que presenta es una variedad inventada, una construcción que tal como la expone no corresponde a ninguna realidad existente. El voseo porteño, sin embargo, es simplemente la forma normal de expresión de todos los porteños (y de muchos más), como lo reconoce ahora también la Academia en sus nuevas obras gramaticales (p. 39).

Algo semejante a lo que afirma Kabatek sobre el capítulo del Quijote de Stavans cabría decir de la traducción de Porrah. La hipercaracterización deformada que hace de la(s) varieda$\mathrm{d}(\mathrm{es})$ lingüística(s) andaluza(s) convierte su propuesta en una caricatura, en un esperpento que puede tener su valor como ejercicio lúdico, cómico, de pasatiempo, pero que resulta peligroso e irresponsable si se utiliza como instrumento de reivindicación de una identidad lingüística andaluza excluyente. El deseo de dignificación del andaluz casa mal con la selección de variantes desprestigiadas por la propia comunidad de hablantes andaluza. Si Porrah quería iniciar el camino para una normalización del andaluz -empresa, por lo demás, innecesaria en estos momentos- debería haber seleccionado exclusivamente fenómenos extendidos por la mayor parte del territorio o, en todo caso, por los que, aun siendo minoritarios porcentualmente, son conocidos y aceptados por la gran mayoría de los andaluces: el seseo, la aspiración (y no en todos los contextos), ciertas variantes léxicas, etc. El mero hecho simbólico de utilizar la grafía $s$ en vez de la $z$, por más que la $s$ evoque en una mayor cantidad de casos soluciones convergentes con el resto de variedades hispánicas, habría sido más coherente con la propuesta de normalización/ estandarización deseada, a pesar de que, 
por el momento, nosotros consideremos inane esta tarea. $\mathrm{Al}$ menos así habría seleccionado un rasgo de una supuesta variedad estándar meridional —en cuanto que representación, en esa comunidad lingüística, de un fenómeno no marcado diastrática ni diafásicamente ${ }^{34}$.

Por supuesto, ni siquiera esa bondad que ha negado Porrah a los lectores habría sido suficiente para justificar una traducción de Le petit prince a un andaluz que, tal como lo pinta (lo escribe) el autor, es inexistente. Su texto representa un intento de estandarización banal, una anécdota cuya repercusión social, por fortuna, parece ya enterrada. La lingüística no tiene mucho más que decir sobre este juego. Pero sí debe contestar con razones y juicio crítico propuestas como las que sigue amparando la Zoziedá pal Ehtudio’el Andalú, así como ofrecer argumentos a las autoridades (sobre todo a las regionales) para que se impida la promoción de instituciones que respalden iniciativas desafortunadas como éstas. Esperamos que nuestro trabajo sirva de argumento para lograr que la sociedad andaluza sea capaz de valorar el andaluz como lo que es: un conjunto de hablas muy reconocibles en cuanto a su manifestación fonética y prosódica cuyo horizonte de referencia sigue siendo el español peninsular, dentro de cuyo espacio variacional se localiza.

\section{REFERENCIAS}

\section{Corpus}

And = Antoine de Saint-Exupéry 2017. Er prinzipito. Trad. Huan Porrah, Tintenfaß, Neckarsteinach.

Esp1 = El principito 2004 [1953]. Trad. Bonifacio del Carril, Alianza, Madrid. Esp2 = El pequeño príncipe 2015. Trad. Sandra Caula, Rialp, Madrid.

$E x t=$ El prencipinu 1999. Trad. Antòniu Garríu Correas, Iberediciones, Madrid.

Mur = Er principico 2016. Trad. José Martínez Aguilar, Diego Marín, Murcia. $O=$ Le petit prince 1999 [1946]. Gallimard, Paris.

${ }^{34}$ La traducción de Sandra Caula ([Esp2]) selecciona algunos rasgos estándares comunes al español en América; por ejemplo, frente a lo que ocurre en [Esp1], emplea ustedes en lugar de vosotros. Sin embargo, su traducción no busca divergir a toda costa de [Esp1], sencillamente porque es más lo que une a todas las variedades del español que lo que las diferencia. 


\section{Referencias bibliográficas}

Alcalá Venceslada, Antonio 1951. Vocabulario andaluz, Real Academia Española, Madrid.

Alonso, Amado 1969 [1951]. "Historia del ceceo y el seseo españoles", en De la pronunciación medieval a la moderna en español, Gredos, Madrid, t. 2, pp. 47-144.

ALEA = Manuel Alvar, Antonio Llorente, Gregorio Salvador y José Mondéjar 1993 [1961-1973]. Atlas lingüistico y etnográfico de Andalucía, Junta de Andalucía, Sevilla, 3 ts.

Alvar EzQuerra, Manuel 2000. Tesoro léxico de las hablas andaluzas, Arco/ Libros, Madrid.

Ariza Viguera, Manuel 1994. "Fonética andaluza en textos escritos. Su valoración lingüística y artificio”, Lingüistica Española Actual, 16, 1, pp. 59-78.

Ariza Viguera, Manuel 1997. "Fonética y fonología del andaluz. Perspectiva diacrónica y sincrónica”, en El habla andaluza. Actas del Congreso del Habla Andaluza (Sevilla, 4-7 de marzo de 1997). Eds. Antonio Narbona y Miguel Ropero, Seminario Permanente del Habla Andaluza, Sevilla, pp. 123-162.

BAKer, Mona 1996. "Corpus-based translation studies: The challenges that lie ahead”, en Terminology, LSP and Translation. Studies in language engineering in honour of Juan C. Sager. Ed. Harold Somers, John Benjamins, Amsterdam-Philadelphia, pp. 175-186.

Bustos Tovar, José Jesús de 2017. "Oralidad y escritura en el siglo xvi: el caso de Santa Teresa”, en Santa Teresa o la llama permanente. Estudios históricos, artísticos y literarios. Eds. Esther Borrego Gutiérrez y Jaime Olmedo Ramos, Centro de Estudios Europa Hispánica, Madrid, pp. 221-243.

Cano Aguilar, Rafael 2008. "Lengua e identidad en Andalucía: visión desde la historia”, en La identidad lingüistica de Andalucía. Coord. Antonio Narbona Jiménez, Fundación José Manuel Lara, Sevilla, pp. 67-134.

Cano Aguilar, Rafael 2013 [2004]. "Cambios en la fonología del español durante los siglos XVI y xviı”, en Historia de la lengua española. Coord. Rafael Cano Aguilar, Ariel, Barcelona, pp. 825-857.

Cheshire, Jenny \& Dieter Stein (eds.) 1997. Taming the vernacular. From dialect to written standard language, Longman, London-New York.

Coseriu, Eugenio 1977. "Sprachliche Interferenz bei Hochgebildeten", en Sprachliche Interferenz: Festschrift für Werner Betz. Hrsg. Herbert Kolb und Hartmut Lauffer, Niemeyer, Tübingen, pp. 77-100.

Coseriu, Eugenio 1980. “"Historische Sprache» und «Dialekt»", en Dialekt und Dialektologie. Ergebnisse des internationalen Symposions "Zur Theorie des Dialekts”. Marburg/Lahn, 5.-10. September 1977. Hrsg. Joachim Göschel, Pavle Ivic und Kurt Kehr, Steiner, Wiesbaden, pp. 106-122.

Del Rey Quesada, Santiago 2011. "Oralidad y escrituralidad en el diálogo literario: el caso de los Coloquios de Erasmo”, en Sintaxis y análisis del discurso hablado en español. Homenaje a Antonio Narbona. Eds. José Jesús de Bustos Tovar, Rafael Cano Aguilar, Elena Méndez García de Paredes y Araceli López Serena, Secretariado de Publicaciones de la Universidad de Sevilla, Sevilla, t. 2, pp. 695-711. 
Del Rey Quesada, Santiago 2015. "Universales de la traducción e historia de la lengua: algunas reflexiones a propósito de las versiones castellanas de los Colloquia de Erasmo", Iberoromania, 81, pp. 83-102; doi: 10.1515/ ibero-2015-0009.

Del Rey Quesada, Santiago 2015a. “¿Qué es lo que oigo? Historia de una fórmula conversacional en el diálogo literario castellano”, Revista Internacional de Lingüistica Iberoamericana (RILI), 26 (sección temática: Oraciones hendidas en el mundo hispánico: problemas estructurales y variacionales), pp. 81-100.

Del Rey Quesada, Santiago 2016. "Interferencia latín-romance en Alfonso X: la traducción como pretexto de la elaboración sintáctica”, La Corónica, 44, 2, pp. 75-109; doi: 10.1353/cor.2016.0004.

Del Rey Quesada, Santiago 2018. "El De senectute de Cicerón en romance (ss. XIV-XVI): un estudio sintáctico contrastivo", Anuari de Filologia. Estudis de Lingüistica, 8, pp. 21-56; doi: 10.1344/AFEL2018.8.2.

Del Rey Quesada, Santiago 2019. "Estructuras participiales y gerundiales en el castellano del s. Xvi: caracterización sintáctica y estatuto variacional”, Revista de Filología Románica, 35, pp. 179-199; doi: 10.5209/ RFRM.63512.

Del Rey Quesada, Santiago 2020. "The analysis of linguistic variation in translation studies. A proposal for classifying translational phenomena between source text and target text”, Hikma. Revista de Traducción, 19, 1, pp. 209-237; doi: 10.21071/hikma.v19i1.12333.

Del Rey Quesada, SAntiago 2021. "Lo marcado y lo no marcado en la cadena de variedades: apuntes para una nueva propuesta", en Was bleibt von kommunikativer Nähe und Distanz? Mediale und Konzeptionelle Aspekte sprachlicher Variation. Hrsg. Teresa Gruber, Klaus Grübl und Thomas Scharinger, Narr, Tübingen, pp. 199-232. (ScriptOralia, 144).

Dufter, ANDreas 2008. "On explaining the rise of $c$ 'est-clefts in French", en The paradox of grammatical change. perspectives from Romance. Coords. Ulrich Detges \& Richard Waltereit, John Benjamins, Amsterdam, pp. 31-56.

FERnÁndez Soriano, Olga 1995. "Pronombres reasuntivos y doblado de clíticos", en De grammatica generativa. Ed. Patxi Goenaga Mendizabal, Universidad del País Vasco, Bilbao, pp. 109-128.

Frago Gracia, Juan A. 1993. Historia de las hablas andaluzas, Arco/Libros, Madrid.

Gutiérrez Ordóñez, SALVAdor 1986. "Estructuras ecuativas y ecuacionales", en Variaciones sobre la atribución, Universidad de León, León, pp. 45-85.

KaвATEк, Johannes 1997. "Zur Typologie sprachlicher Interferenzen”, en Neue Forschungsarbeiten zur Kontaktlinguistik. Hrsg. Wolfgang W. Moelleken und Peter J. Weber, Dümmler, Bonn, pp. 232-241.

Kabatek, Johannes 2018. "Traducción y dignificación lingüística”, en Lenguas en contacto, ayer y hoy. Traducción y variación desde una perspectiva filológica. Eds. Santiago del Rey Quesada, Florencio del Barrio de la Rosa y Jaime González Gómez, Peter Lang, Frankfurt/M., pp. 25-44; doi: $10.3726 / \mathrm{b} 15393$.

Koch, Peter y Wulf Oesterreicher 2007 [1990]. Lengua hablada en la Romania: español, francés, italiano. Versión española de Araceli López Serena, Gredos, Madrid. 
LAPESA, RAFAel 1985 [1957]. "Sobre el seseo y el ceceo andaluces", en Estudios de historia lingüistica española, Paraninfo, Madrid, pp. 249-266.

Lope Blanch, Juan Miguel 1987 [1983]. Análisis gramatical del discurso, Universidad Nacional Autónoma de México, México.

López Serena, Araceli 2007. Oralidad y escrituralidad en la recreación literaria del español coloquial, Gredos, Madrid.

López SERena, Araceli 2019. La lingüistica como ciencia humana. Una incursión desde la filosofía de la ciencia, Arco/Libros, Madrid.

Marín Hernández, David 2019. "Un caso de traducción identitaria: Le petit prince en andaluz", Meta, 64, 1, pp. 78-102; doi: 10.7202/1065329ar.

MARTín GonzÁlez, JAVIER 2017. "La discriminación de la realidad lingüística andaluza", La Voz del Sur, en https://www.lavozdelsur.es/la-discriminacion-de-la-realidad-linguistica-andaluza/ [consultado el 30 de julio de 2019].

Méndez García de Paredes, Elena 2009. "La proyección social de la identidad lingüística de Andalucía. Medios de comunicación, enseñanza y política lingüística”, en La identidad lingüistica de Andalucía. Coord. A. Narbona Jiménez, Fundación José Manuel Lara, Sevilla, pp. 213-319.

Méndez García de Paredes, Elena 2011. "Si yo fuera estado allí, no fuera pasado eso. Pervivencia de un aparente arcaísmo en la lengua de internet", en Sintaxis y análisis del discurso hablado en español. Homenaje a Antonio Narbona. Eds. J.J. de Bustos Tovar, R. Cano Aguilar, E. Méndez García de Paredes y A. López Serena, Secretariado de Publicaciones de la Universidad de Sevilla, Sevilla, t. 2, pp. 1009-1031.

Méndez García de Paredes, Elena 2019. "Posiciones enunciativas e ideología en los discursos metalingüísticos sobre la variedad andaluza en la prensa española. De 1977 a la actualidad", en Ideología sobre la lengua en los medios de comunicación escritos. El caso español. Eds. Carmen Marimón Llorca y M. Isabel Santamaría Pérez, Peter Lang, Berlin, pp. 193-215.

Méndez García de Paredes, Elena y Carla Amorós Negre 2018. "The status of Andalusian in the Spanish-speaking world: Is it currently possible for Andalusia to have its own linguistic standardization process?", Current Issues in Language Planning, 19, 2, 179-198; doi: 10.1080/14664208.2018.1495369.

Menéndez Pidal, Ramón 1962. "Sevilla frente a Madrid. Algunas precisiones sobre el español de América”, en Miscelánea-homenaje a André Martinet: "estructuralismo e historia”. Ed. Diego Catalán, Universidad de La Laguna, Canarias, t. 3, pp. 99-165.

Milroy, James 1992. Language variation and change, Blackwell, Oxford.

MondéJAR, José 1990. "Andalucismo ambiental y andalucismo lingüístico en el teatro de los hermanos Machado", en Antonio Machado, hoy. Actas del Congreso Internacional Conmemorativo del cincuentenario de la muerte de Antonio Machado, Alfar, Sevilla, t. 2, pp. 137-158.

MondéJAR, José 1994. El verbo andaluz. Formas y estructuras, Ágora, Málaga.

MondéJAr, José 2001. Dialectología andaluza. Estudios, $2^{\mathrm{a}}$ ed. Eds. Pilar Carrasco y Manuel Galeote, Universidad de Málaga, Málaga, 2 ts.

Narbona Jiménez, Antonio 1999. "Diversidad y dinamismo del habla andaluza. ¿Normalizar el andaluz?”, en Foro Andalucía en el nuevo siglo: 
reflexiones y propuestas. Ed. Roberta Castiñeira González, Consejería de la Presidencia, Sevilla, pp. 139-165.

Narbona Jiménez, Antonio 2001. "Diálogo literario y escritura(lidad)-oralidad”, en Diálogo y oralidad en la narrativa hispánica moderna. Perspectivas literarias y lingüisticas. Ed. Rolf Eberenz, Verbum, Madrid, pp. 189-208. [Ahora también en Narbona Jiménez 2015, pp. 331-344].

Narbona Jiménez, Antonio 2009. "La identidad lingüística de Andalucía", en La identidad lingüistica de Andalucía. Coord. A. Narbona Jiménez, Fundación José Manuel Lara, Sevilla, pp. 23-66.

Narbona Jiménez, Antonio 2015. Sintaxis del español coloquial, Editorial de la Universidad de Sevilla, Sevilla.

Narbona Jiménez, Antonio, Rafael Cano Aguilar y Ramón Morillo-VeLARde PÉrez 2003. El español hablado en Andalucía, Fundación José Manuel Lara, Sevilla.

Roggia, Carlo Enrico 2009. Le frasi scisse in italiano. Struttura informativa e funzioni discorsive, Éditions Slatkine, Genève.

Toury, Gideon 1995. Descriptive translations studies and beyond, John Benjamins, Amsterdam.

Villena Ponsoda, Juan Andrés 2008. "La formación del español común en Andalucía. Un caso de escisión prestigiosa”, en Fonología instrumental. Patrones fónicos y variación. Eds. Esther Herrera Zendejas y Pedro Martín Butragueño, El Colegio de México, México, pp. 211-253.

Villena Ponsoda, JuAn Andrés 2008a. "Divergencia dialectal en el español de Andalucía: el estándar regional y la nueva koiné meridional”, en Lenguas en diálogo. El iberorromance y su diversidad lingüistica y literaria. Eds. Hans-Jörg Döhla y Raquel Montero-Muñoz, Iberoamericana-Vervuert, Madrid-Frankfurt/M., pp. 369-392.

Villena Ponsoda, JuAn ANDRés 2016. "Variación lingüística y traducción. Por qué el traductor necesita del variacionista”, en Variación lingüistica, traducción y cultura. De la conceptualización a la práctica profesional. Eds. Giovani Caprara, Emilio Ortega Arjonilla y Juan Andrés Villena Ponsoda, Peter Lang, Bern, pp. 9-118.

Weinreich, URIEL 1967 [1953]. Languages in contact. Findings and problems, Mouton \& Co., London-Den Haag-Paris. 